\title{
Indoor Location Identification Technologies for Real-Time IoT-based Applications: An Inclusive Survey
}

\author{
George Oguntala ${ }^{1 *}$, Raed Abd-Alhameed ${ }^{1}$, Stephen Jones ${ }^{1}$, James Noras ${ }^{1}$, Mohammad Patwary ${ }^{2}$, Jonathan \\ Rodriguez $^{3}$ \\ ${ }^{1}$ School of Electrical Engineering and Computer Science, University of Bradford, West Yorkshire, UK \\ ${ }^{2}$ School of Computing and Digital Technology, Birmingham City University, Birmingham, UK \\ ${ }^{3}$ IT-Aveiro Instituto de Telecommunicacoes, Campus Universitario de Santiago, Portugal
}

\begin{abstract}
The advent of the Internet of Things has witnessed tremendous success in the application of wireless sensor networks and ubiquitous computing for diverse smart-based applications. The developed systems operate under different technologies using different methods to achieve their targeted goals. In this treatise, we carried out an inclusive survey on key indoor technologies and techniques, with to view to explore their various benefits, limitations, and areas for improvement. The mathematical formulation for simple localisation problems is also presented. In addition, an empirical evaluation of the performance of these indoor technologies is carried out using a common generic metric of scalability, accuracy, complexity, robustness, energy-efficiency, cost and reliability. The empirical evaluation of the performance of different RF-based technologies establishes the viability of Wi-Fi, RFID, UWB, Wi-Fi, Bluetooth, ZigBee, and Light over other indoor technologies for reliable, IoT-based applications. The survey advocates for increased hybridization of technologies as an effective approach to achieving reliable IoT-based indoor systems. Furthermore, the findings of the survey could be useful in the selection of appropriate indoor technologies for the development of reliable real-time IoT-based indoor applications. The study could also be used as a reliable source for literature referencing indoor location identification.
\end{abstract}

Index Terms: Indoor Localization, Internet of Things, Indoor technologies, Hybridisation

\section{Introduction}

7 he numerous breakthroughs in the Internet of Things (IoT), have invariably enabled the requirement for accurate real-time location information by most applications for tracking of people and objects $[1,2]$. Location identification involves the determination of the spatial position of targets using different possible methods with key parameters including precision, accuracy, cost, reliability, scalability, energy efficiency and robustness [3]. The range of pervasive applications using real-time location-based information is diverse, with many applications regardless of the environment are required to operate independently and intelligently [4]. Thus, these key parameters become some prime design requirements.

The progress achieved in the research of outdoor applications is remarkable in recent times. With the Global Positioning System (GPS), a reliable and accurate location identification is possible for diverse outdoor applications whenever there is a direct line of sight (LOS) between the satellites and its receiver [5, 6]. The GPS remains a prime example of the relatively high localisation accuracy obtainable through very long distance wireless communication link with effective global coverage of over $10 \mathrm{~m} \mathrm{[7,8].} \mathrm{However,} \mathrm{the} \mathrm{level} \mathrm{of} \mathrm{accuracy}$ of GPS become unreliable in indoor environments, often affected by several factors including multipath from reflections of signals by walls and ceiling, NLOS (non-line-of-sight), attenuation and signal scattering, noise, and physical obstruction of signals [9-12]. The unreliability of GPS indoors necessitates the search for alternative exciting, innovative methods for efficient location-based applications.

\footnotetext{
* Corresponding author.

Email addresses: G.A.Oguntala@bradford.ac.uk (G. Oguntala), R.A.A.Abd@bradford.ac.uk (R. Abd-Alhameed),

S.M.R.jones@bradford.ac.uk (S. Jones), J.M. Noras@bradford.ac.uk (J. Noras), Mohammad.Patwary@bcu.ac.uk (M. Patwary),

Jonathan@av.it.pt (J. Rodriguez)
} 
Indoor location identification or simply indoor localization is an interesting research field that is receiving intense attention due to the high demand for smart location-based application and services within diverse indoor environments [13-21]. In addition, since most people assign a sizeable amount of their time (over $80 \%$ ) indoors to perform various activities, accurate information of the position or location of people for diverse purposes becomes a necessary compulsion. From Fig 1, indoor localisation can be categorized as active or passive, based on the participation of the target in the location identification process. Active location identification is reliant on target action, basically, dedicated devices or tags are attached to targets for communication with dedicated servers to identify their position. Conversely, passive location identification locates people and target objects without their action. Target object and people are often unaware of passive location identification system's existence, barring any legal restrictions a prior location identification. Based on this category, indoor location identification can be subdivided into device-based or device-free. Most active location identification systems are device-based, whilst passive location identification is usually device-based and device-free. In device-based location identification, the target wears a device (RFID tags, mobile devices) that is located by other devices. As an example, a patient with an RFID tag band can be tracked from the RSS between the RFID tag band and the reader nearby. The concept of device-free location identification was first introduced in [22] for the location identification of a non-equipped entity. In device-free location identification, location identification or tracking is achieved explicitly through the interaction of the human body with radio signals in the form of reflection, absorption, scattering and/or diffraction. Though most classic indoor location identification involves the active, and or device-based location identification. However, with the introduction of the Internet of Things (IoT), migration into device-free location identification research has intensified bringing diverse innovative applications such as smart homes, smart building, and smart city.

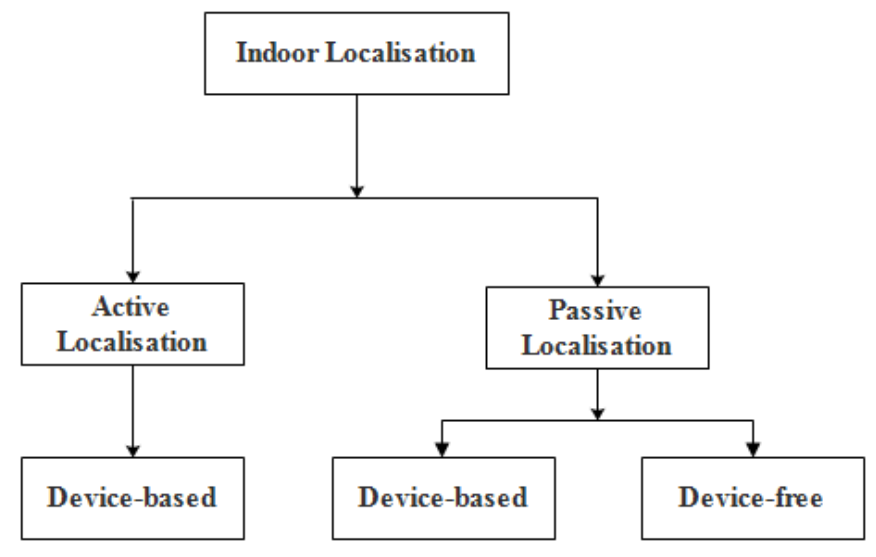

Fig.1. Schemes of indoor location identification

Furthermore, among the various methodological technologies used for indoor localisation include ultrasound [23], infrared [24], Wi-Fi (IEEE 802.11) [25, 26], Bluetooth (IEEE 802.15) [27, 28], ZigBee [29, 30], Ultrawide Band (UWB) [31, 32], inertial navigation [33], magnetic-based methods [34, 35] and Radio Frequency Identification (RFID) [36-38]. These technologies differ in scope, method, location type; symbolic or geometric, and cost bringing a suitable level of diversity to indoor location identification. Moreover, indoor location identification is applied for a diverse range of applications including fitness monitoring [39], healthcare [40, 41], building automation [42, 43], security [44], automated activity and assisted living [45-47], retail [48], pedestrian navigation [49] and smart parking [50]. Indoor location identification becomes a more challenging research due to the requirement of indoor location-based applications and systems to achieve high accuracy and precision in presence of the complexities of the indoor environment. In effect, achieving accurate indoor systems with preferably sub-meter level location error often presents a daunting task. Nonetheless, many location identification systems have been proposed and developed to address these challenging issues with most of these emerging indoor systems making huge ROI on deployment [51]. In addition, these innovative location identification systems are constantly raising the bar of demand for real-world indoor deployment that is both cost-effective and accurate [52]. Nevertheless, most existing indoor location identification systems suffer from one form of limitation or another, which affect their overall performance. 


\subsection{Motivation of the Survey}

In today's world, the Internet of Things (IoT) has become the de facto concept in engineering and computing due to the vision of global infrastructure interconnectivity. IoT involves the combination of different emerging technologies such as an embedded sensor, localization, near-field communication, and the internet. IoT supports the integration of objects, devices, and systems equipped with sensors and microcontrollers to interacts with one another and their users [53]. Moreover, since most people usually expend a considerable amount of time daily within various indoor environments for different purposes, location identification becomes an interesting research area for safety and emergency measures. Therefore, the motivation for conducting this survey is to carry out an intense appreciation of the methods, technologies, and techniques used to achieve efficient location identification. This will help new and existing researchers in the research field to elucidate and characterize viable technologies to design innovative IoT-based location identification applications and system. However, we shall take "location identification" to mean "indoor location identification", to avoid repetition.

The remaining article is structured as follows. A review of the different location identification technologies with different experimental simulations of some of the technologies are covered in Section 2. Section 3 highlights the various techniques used for measuring the propagating signal using the different indoor technologies. In section 4, we formulate a simple location identification problem using two key techniques. Section 5 presents the key evaluation metrics used to measure the generic results obtained. A discussion on the generic evaluation and sampled comparison of RF-based technologies is presented in Section 6. Section 7 concludes the survey.

\section{Location identification Technologies}

In this section, we cover the various positioning and location identification technologies. The operating principles of each indoor technology which include sound, photonics, mechanics, radio frequency, and environmental factors are also highlighted. Moreover, a real-world experimental example of each technology is a showcase for a deeper appreciation of each technology for various position and location-based applications. Nonetheless, a comprehensive overview of this section is presented in Fig. 2.

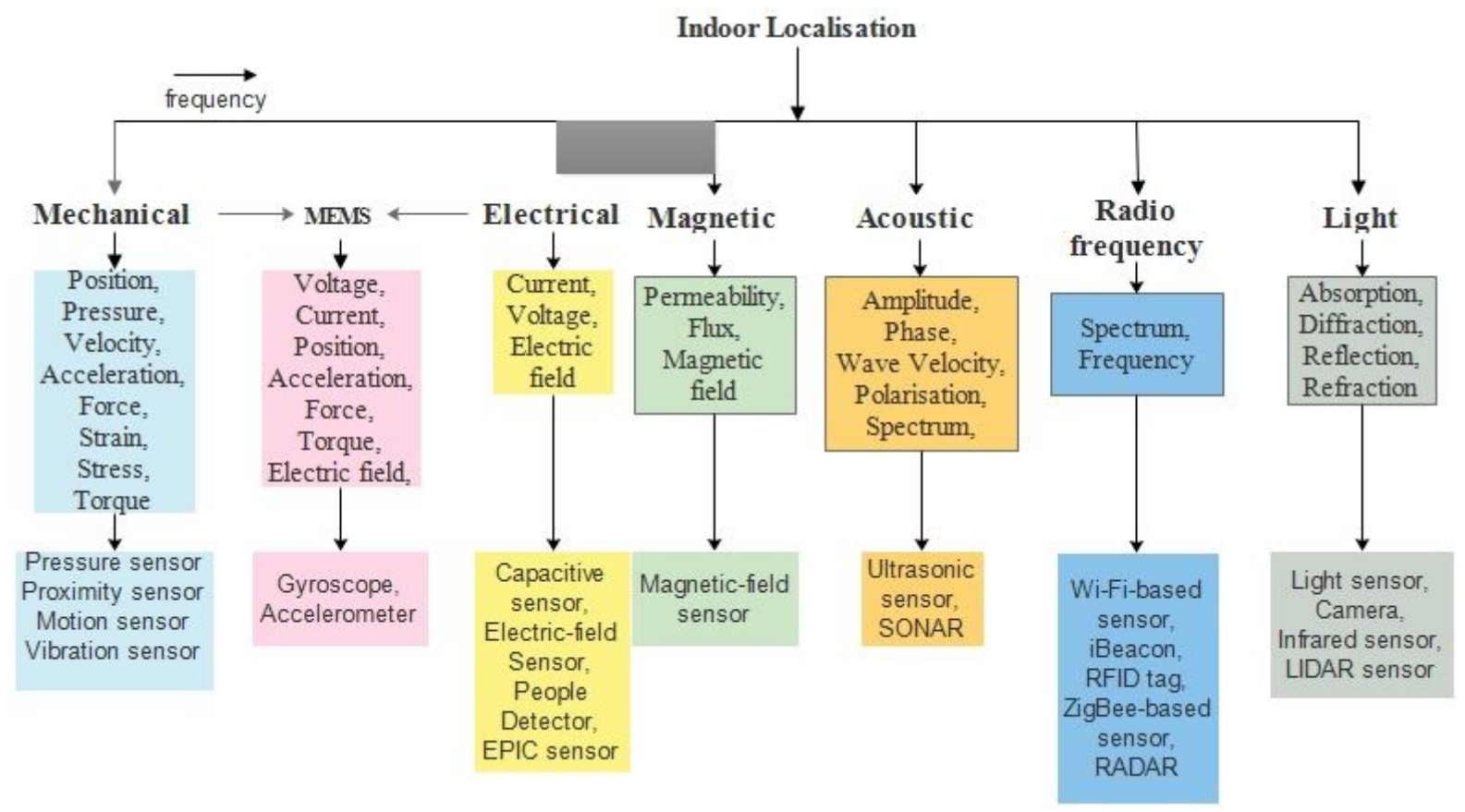

Fig 2. Taxonomy of location identification technologies and various devices deployed under each field ${ }^{\dagger}$

\footnotetext{
${ }^{\dagger}$ The block between the electric and magnetic technology indicates that both technologies operates around the same frequency.
} 


\subsection{Mechanical-based}

Inertial navigation system (INS) is a composite indoor/outdoor location identification technology that utilizes inertial measuring units (IMU) such as accelerometer and gyroscope, for determining the position and angular motion of target objects relative to an initial starting point, angle and velocity. Inertial navigation also referred to as reduced reckoning, is useful in determining the position of the target object using the measurement of previously-estimated position along with the speed and direction of the target object. INS was initially designed for outdoor applications (such as aircraft), but have proved over time as an effective indoor technology due to its high accuracy, high mean time between failure (MTBF) and efficient energy management [54]. However, most INS-based applications are invasive and obtrusive since the inertial sensor must be attached to the surface area of the target. The strap-down system of INS, which are the micro-machined electromechanical systems (MEMs), possesses several desirous features for location identification such as miniaturized size and weight, low power consumption, cheap in cost and short start-up time [55]. Fig. 3 highlights a real-time INS-based experiment using a wireless IMU for estimating the motion and orientation of targets.

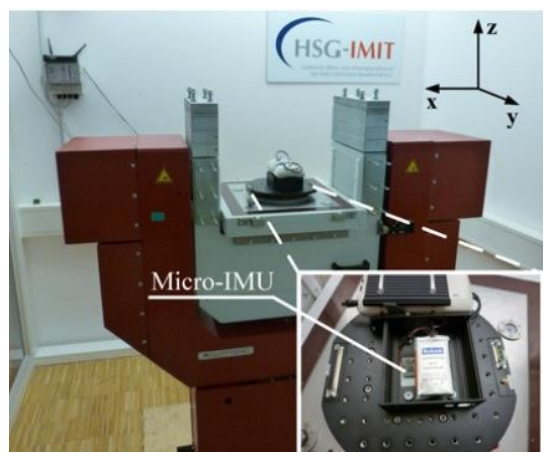

(a). An experimental setup using micro-IMU

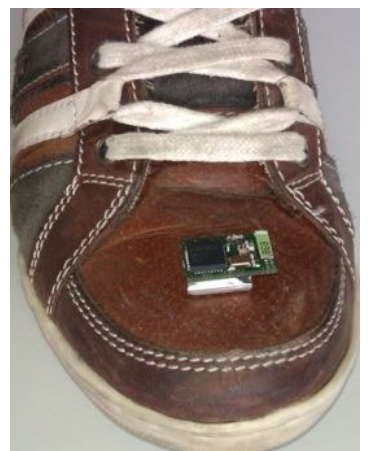

(b) A micro-IMU V2 with chip antenna mounted on a shoe for motion and orientation determination

Fig. 3. A wireless INS-based experiment and its target application (Source: Holfinger et al. [56])

Moreover, because INS involves the estimation of target position from a known initial position using direction and speed measurement, it is subjected to drift and cumulative error, which necessitates the implementation of the location identification approach using filtering methods such as Kalman filtering.

\subsection{Acoustic}

Ultrasound-based location identification utilizes the TDoA measurement of the acoustic pulse transmitted by the audio beacon generator (ABG) to a number fixed or mobile client device (e.g. smartphones, laptop...) deployed at particular mapped locations for indoor positioning [57]. The ABG broadcasts its acoustic signal that is encoded with the uniform resource locator (URL) of the web-based service, in form of a service code mapped to a particular location or service, such that surrounding client devices attached to the mobile target can thus identify themselves within the particular mapped location [58], as the location of the mobile target is processed by a specialized communication algorithm run on a web-based server. Fig. 4 highlights an example of a target location identification in a crowded office space using an acoustic sensor.

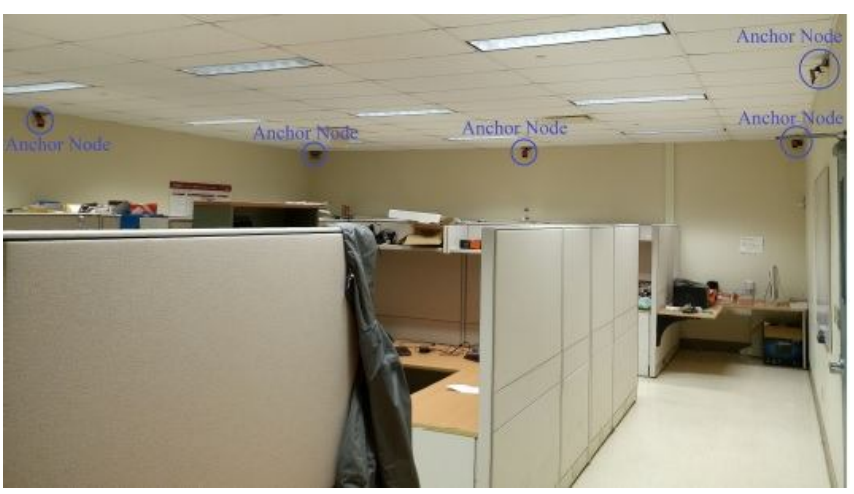

(a). A general crowded office environment deployed with acoustic sensors

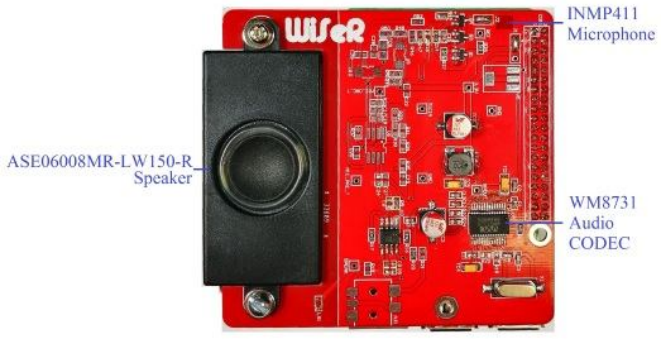

(b) An acoustic microcontroller board 
Fig. 4. An acoustic-based indoor localization experiment using acoustic sensors (Source: Wang et al. ) [59]

Ultrasound has several attractive features such as negligible penetrating power in walls, cheap transducers, and hardware compatibility with almost all handheld devices. Generally, the ultrasound-based approach offers higher accuracy and is suitable for short-range applications, thus scaling up the coverage area will incur higher deployment cost [60]. In addition, the time of flight method often used in the signal propagation to estimate the distance between the receivers and the transmitting object do require synchronization between the sensor nodes, which is practical in an electrical pulse system of wired connection, but unreliable in a wireless network [61]. However, due to the relatively slow speed of sound (i.e. around 344 meter/seconds), ultrasound location identification is affected by scattering owing to the reflection of the acoustic pulse resulting in reverberation. In addition, ultrasound location identification is affected by inconsistent frequency due to Doppler shift effect.

\subsection{Magnetic-based technology}

Magnetic-based location identification system utilizes the effect of the magnetic field since it is vectorial in nature, for localizing the position of target objects. Location identification is achieved using reference stations which generate a periodic magnetic field that can be measured by a mobile magnetic sensor. The position of the mobile target is localized from the measurement of the magnetic field strength of the magnetic field sensor equipped with the mobile target of at least three reference station using trilateration approach [62]. Magneticbased location identification offers high accuracy on the order of few centimeters and degrees at $10 \mathrm{~Hz}$.

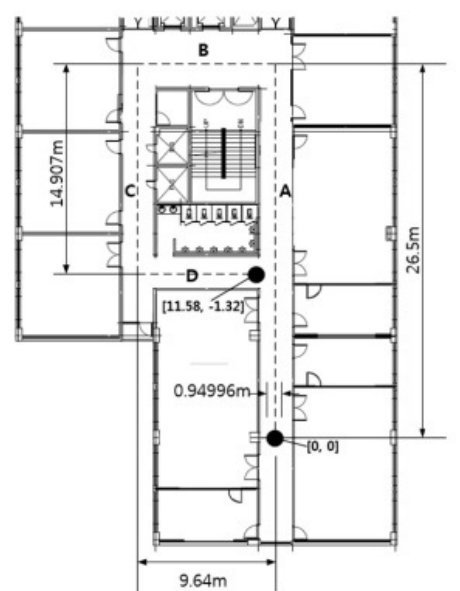

(a) Example of the test area

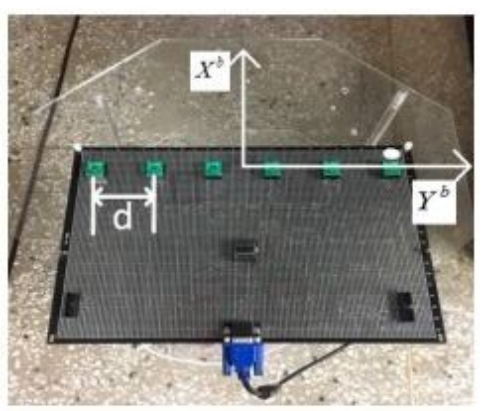

(c) A magnetic sensor array board

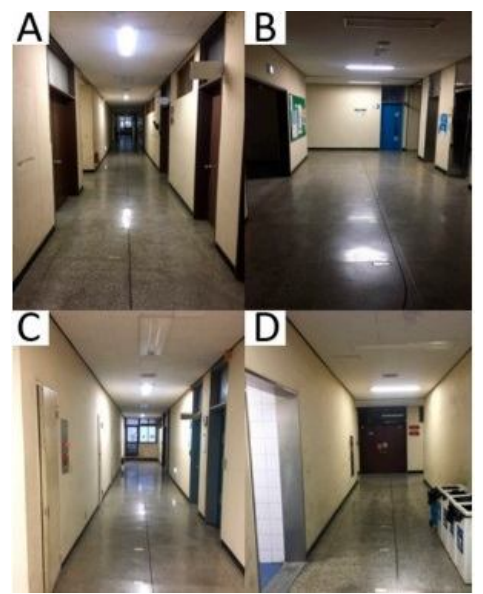

(b) Actual test area for magnetic map navigation

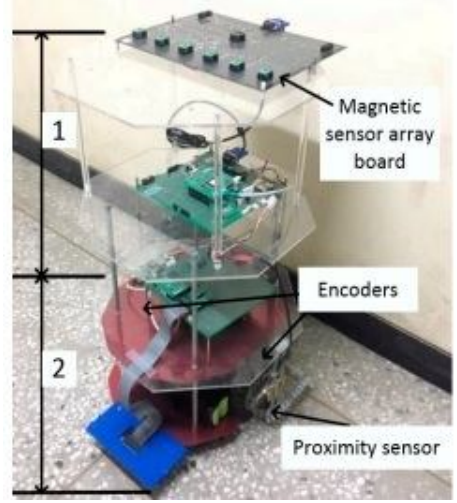

(d). Mobile robot system attached with the magnetic sensor

Fig. 5. A real-world example of magnetic field mapping for indoor navigation using a mobile robot system (Source: Kim et al) [63]

Here, Fig. 5 shows a real-world example of magnetic field mapping using a mobile robot system for sampling the indoor environment. Moreover, unlike most location identification technologies, magnetic-based location identification has the potential for no federal communication commission (FCC) since they operate at low 
frequencies, lower to those censored by the FCC. However, the reliability of magnetic-based location identification is challenged owing to their sensitivity to conductive and ferromagnetic materials.

\subsection{Optical-based location identification}

Infrared operates on the principle that infrared wavelengths are longer than visible light, although shorter than ultraviolet. Infrared is less intrusive, owing to the invisible nature of infrared signal to the human eyes under virtually all conditions. Infrared-based location identification employs three methods based on (i) active beacons [64] (ii) thermal radiation [65] and (iii) artificial light sources [66].

- The active beacon method uses infrared receivers placed in different known locations and mobile beacons on target objects whose positions are unknown, such that with an IR location identification system, the unknown positions can be estimated.

- The thermal infrared radiation method exploits the natural thermal radiation of humans. Detection using this method usually occurs by the combined estimation of the sensor measurement within the coverage area using passive, low-resolution sensors, easy to integrate into any existing environment. The full anonymity of the localized target object is achieved when low-resolution sensors are used, making identification of the heat sources practically impossible, [67, 68].

- The artificial light source method utilizes a set of infrared light emitting diodes (LEDs) and usually a phototransistor. Light modulated at a frequency of $38 \mathrm{kHz}$ is passed through a phototransistor with a filter, such that interference between the modulated light and other illuminating sources such as sunlight can be reduced. Each LED emits a unique ID depending on the pulse train of the modulated light. Location identification occurs when each LED installed at specified locations in a coverage area emits a unique ID, whereas the LED tracker determines the location of the two-dimensional location of the LED in the sight of its infrared image sensor by recognizing the unique ID of each LED [69].

Infrared technology using a light source and other methods offer some advantage over RF-based technology in that, light signal suffers negligible reflection, thus it is not significantly affected by multipath effect compare to RF signals which are affected by multipath effects [70]. Infrared technology is also cheap and reliable for open space applications. However, the technology always requires a line of sight for its signal propagation, making it suitable only for short-range applications. Accuracy is dependent on factors such as physical obstruction, long computational time and low data rate [71].

\subsection{Radio frequency-based location identification}

\subsubsection{WLAN/Wi-Fi (IEEE 802.11g)}

WLAN or Wi-Fi is a technological communication standard for wireless data transmission, which operates between $2.4 \mathrm{GHz}$ and $5 \mathrm{GHz}$ and recently in the $60 \mathrm{GHz}$ frequency band of the electromagnetic spectrum, i.e. Wi-Fi utilizes electromagnetic waves for the transmission of data. The effective range of Wi-Fi is comparably large with a coverage range of between 50 to $100 \mathrm{~m}$ [72, 73]. Wi-Fi signals are often used opportunistically for location identification as highlighted in an experiment shown in Fig 6, which offers an accuracy of around a few meters in an adequately examined environment with dense Wi-Fi coverage [74],

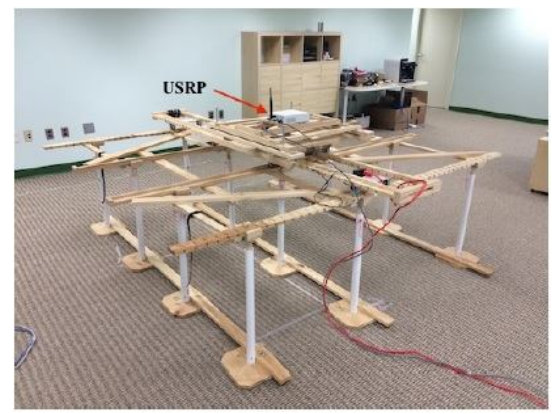

Fig. 6. An experimental measurement of subcarriers in Wi-Fi to achieve highly accurate indoor localization (Source: Chen et al) [75] 
Wi-Fi-based location identification focusses on RSS and fingerprinting methods for target object positioning [73], and these methods are easy to compute since most standard compliant devices utilize the RSS, which is suitable for position estimation [76] and signal-to-noise ratio of the transmitted signal from the wireless devices to position mobile target [77]. Moreover, with the intense research in location identification using CSI of wireless devices, the accuracy of location identification systems improves significantly using Wi-Fi signals and CSI of communication links resulting increased overall performance [78-80]. Thus, location identification using Wi-Fi signal is an attractive approach for estimating the location of mobile targets due to its availability in many environments, with relatively cheap transceivers. However, for an object to be localized, the object must also support the Wi-Fi system.

\subsubsection{Bluetooth}

Bluetooth operates in an analogous way as Wi-Fi, as it transmits radio signals at the same frequency and utilizes the same location identification principles for several applications. Bluetooth is a highly ubiquitous technology, as it operates in the $2.4 \mathrm{GHz}$ unlicensed frequency band, which makes the technology pervasively available, deployable for a wide variety of applications $[81,82]$ including collaborating with other network services $[83$, 84]. The availability of Bluetooth also contributes to it being relatively cheap. Bluetooth operates by specifying a set of mandatory protocols for each Bluetooth module that must be implemented. Fig. 7 highlights the deployment of a Bluetooth iBeacon for localization of a target.
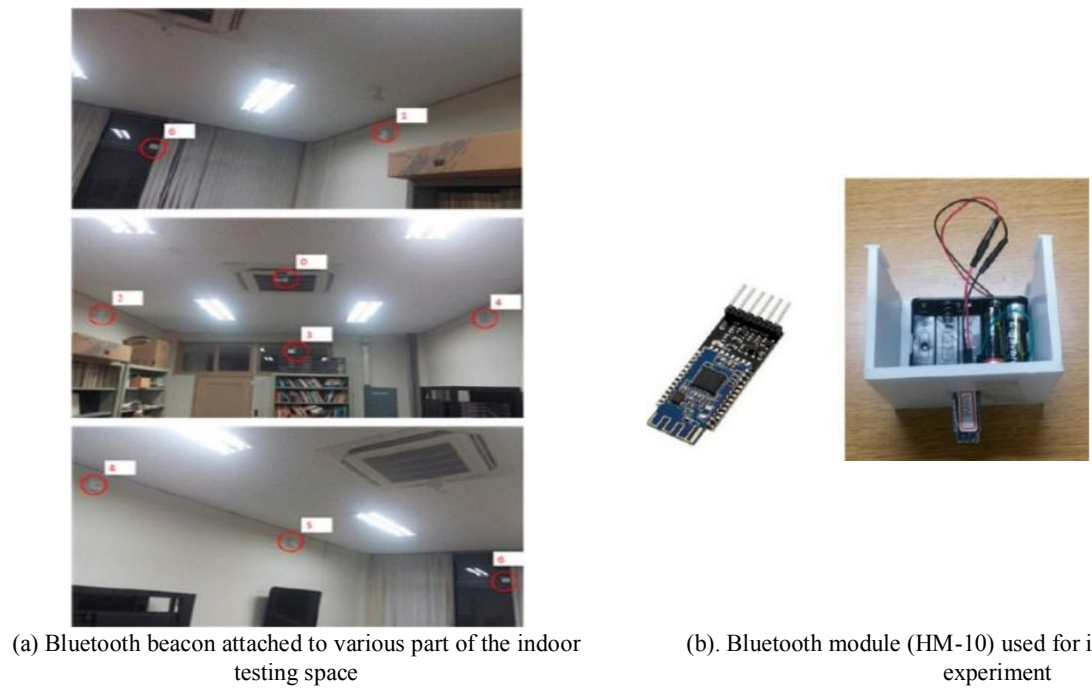

Fig. 7. A deployment of Bluetooth technology using an iBeacon for location detection (Source: Huh et al.) [85]

Like other RF-based technology, Bluetooth is short-ranged and supports low power wireless connections [86]. Bluetooth often has an effective bit rate of $1 \mathrm{Mbps}$ and a precision range of 1 to $5 \mathrm{~m}$ which makes it less effective for longer-range applications [87].

\subsubsection{ZigBee (IEEE 802.15.4)}

ZigBee is a wireless standard defined by a set of communication protocols designed for wireless personal area networks, thereby making it a short-range technology. Wireless devices using ZigBee operate in the $868 \mathrm{MHz}$, $915 \mathrm{MHz}$, and $2.4 \mathrm{GHz}$ ISM band. The effective signal range of ZigBee is up to $100 \mathrm{~m}$ in free space [88-91], and typically 20 to $30 \mathrm{~m}$ in indoor environments [7]. ZigBee is suitable for most low power consumption applications of about $60 \mathrm{~mW}$ with a data rate of about $250 \mathrm{kbps}$, and its devices can function either as a coordinator or as a slave. The coordinating ZigBee device forms the root of the network by initiating a connection between other networks and nodes of up to 255 nodes, whereas the node receives data from the coordinator [92]. 

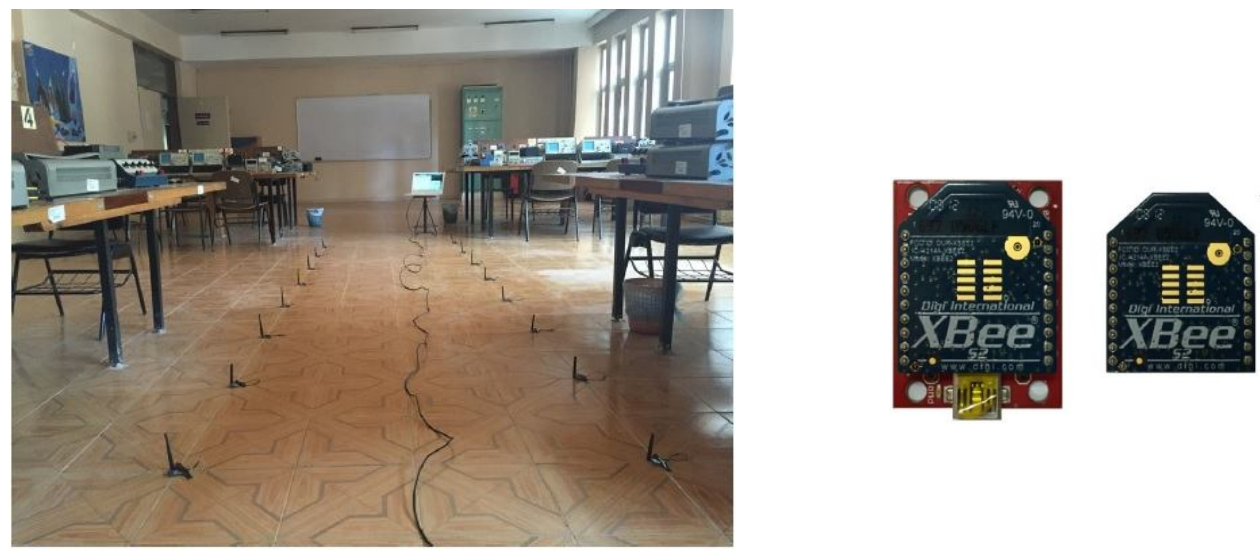

Fig. 8. (a). An experimental environment using ZigBee technology (b). XBee - A ZigBee series 2 module (Source: Aykac et al.) [93] From Fig. 8, we show an established experimental deployment of ZigBee technology for indoor positioning using an XBee module. Furthermore, ZigBee uses the RSS method for distance estimation between two or more ZigBee nodes [94]. ZigBee offers several desirable advantages as described in the literature by several researchers [90, 95-100]. However, ZigBee suffers from some drawbacks as well, as the operating frequency of ZigBee, which lies in the unlicensed ISM band, makes the technology prone to interference from signals operating at the same frequency. In addition, since the technology is only suitable for short-range applications with low-data-rate [101], the range of applications is limited [89].

\subsubsection{Ultra-Wide Band Technology}

Ultra-Wideband (UWB) technology exploits the diverse interactions between electromagnetic fields and matter [102], operating on the principle that images gained from scattering of electromagnetic waves provide a detailed geometrical dimension of the surrounding environment since wavelengths are smaller compared to the real size of objects [103]. Although, electromagnetic scattering does not reveal detailed information of certain objects, for example, opaque and hidden objects. UWB is designed to operate in the microwave frequency occupying a very large bandwidth of more than $1.5 \mathrm{GHz}$ [104], thereby giving the technology an exceptionally high resolution but low penetrating power especially to most non-metallic materials for easy detection of hidden objects. In addition, the higher bandwidth of microwave frequency enables UWB-based location identification to achieve higher object resolution in the decimetre, centimetre, and millimetre range, and better object recognition capabilities than narrowband technologies $[102,105,106]$. Fig. 9 illustrates the application of UWB technology for localization in a large indoor environment.

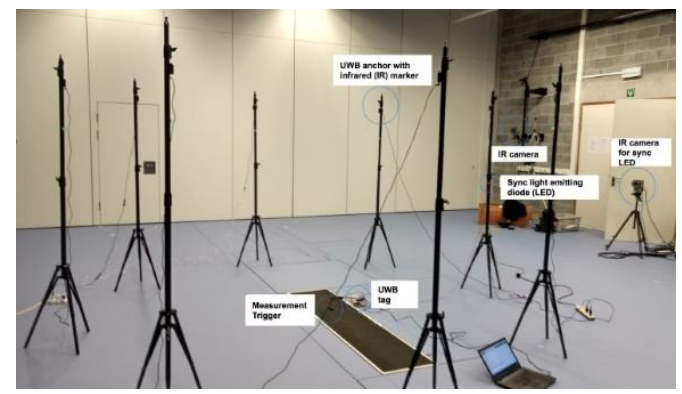

Fig. 9. An indoor localization experiment at the Sports Science Laboratory-Jacques Rogge, Ghent University using eight UWB anchors installed to position a mobile tag. (Source: Ridolfi et al.) [107]

Moreover, since UWB operates by sending ultra-short pulses with low duty cycle across many frequencies [108], this enables the technology to provide accurate ToA positioning information even in the presence of multipath. Other desirable features of UWB include high data rate that is short-range at very low power density $[109,110]$, low EM radiation and low processing energy consumption [111]. However, the large bandwidth of UWB causes inevitable interference in the presence of other devices, thereby necessitating a strict low power consumption limit, which makes the technology a conservative approach and impractical for many location identification applications [112-114]. 


\subsubsection{RFID}

RFID is a pervasive technology, effective for tracking and positioning. RFID systems usually consist of tags, readers, and a server equipped with RFID middleware, thus RFID technology is often categorized as either tagoriented or reader-oriented. RFID tags are made up of transceivers and a chip and can be active, passive and semi-active depending on the availability of power for their functioning. Each tag is uniquely identifiable and able to transmit stored data, which may be read-only or writable. Active tags are equipped with an inbuilt battery embedded in their circuitry, while passive tags do not have inbuilt batteries but backscatter the signal received from the base station. Semi-active tags, although they do backscatter the carrier signal received from a base station, also have an inbuilt battery embedded in their circuitry, which powers the circuitry, thereby giving it the flexibility to function in dense environments [115]. Fig. 10 illustrates the experimental application of RFID technology using passive tags to determine the various categories of activity performed within the mock room. RFID is popular and is useful for a wide variety of applications owing to its cognitive intelligence [116118], and wireless sensing functionality as highlighted in Fig. 10 where RFID technology is applied for activity recognition. RFID offers other desirable advantages which include high data rate, adaptability to various environment, availability in non-line-of-sight (NLOS), wireless capability, wireless zero-power sensors and low maintainability $[18,119-121]$.

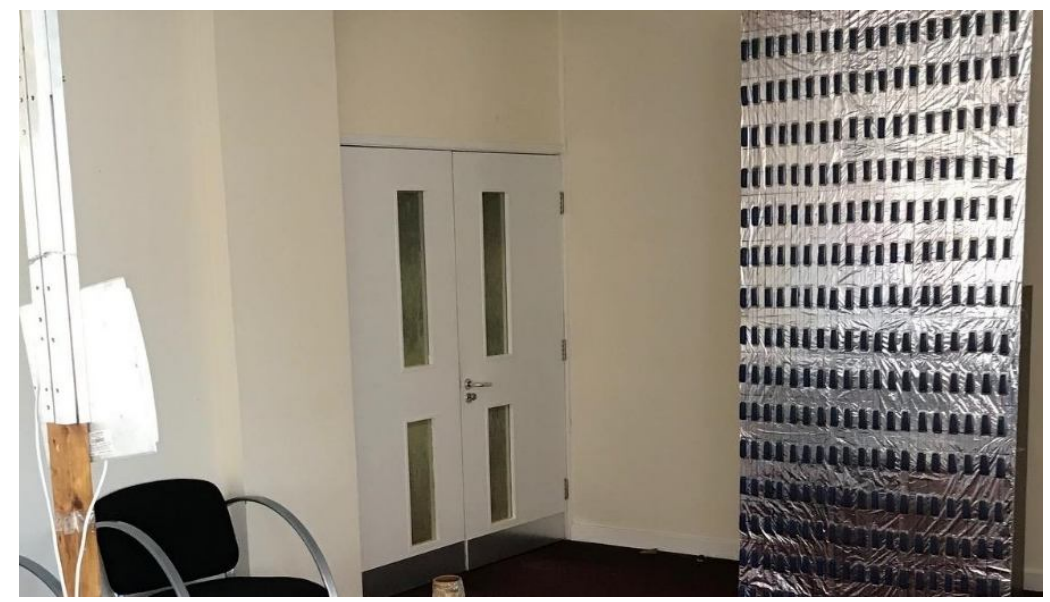

Fig. 10: An indoor localization experiment using passive RFID tags for touchless activity recognition [122]

RFID technology, however, suffers from several limitations arising from the issue of operating frequency standardization, invasive nature, and requirement of additional infrastructure in location identification techniques like proximity [123]. Furthermore, improved accuracy and higher resolution often require the deployment of several tags around the coverage area of interest, which sometimes results in high computational cost.

\subsection{LIDAR}

LIDAR (Light Detection and Ranging) also known as laser radar is an efficient remoting sensing, outdoor/indoor technology, which originated in the early 1960s. LIDAR technology operates on the principle of light propagation and the time it takes the transmitted signal to returns from its source. LIDAR systems operate by emitting near-infrared laser pulse at a high rate of typically $10^{4}-10^{5}$ per second. The precise position and attitude of the laser scanner unit at the time each pulse is emitted is determined from the flight data collected by the reference units. The distance between the scanner and a target that reflects the pulse is computed using the return time of the pulse to complete the return trip distance from the scanner to target. The distance information, position and orientation of the scanner are used to calculate the precise coordinate for each reflection points represents each target location [124]. Therefore, as illustrated from Fig 11, mobile LIDAR sensor are reliable to provide $2-D / 3-D$ points cloud with intensity information for precise acquisition of dense surface information that supports the enhancement of MMS in high depth indoor environments [125]. 


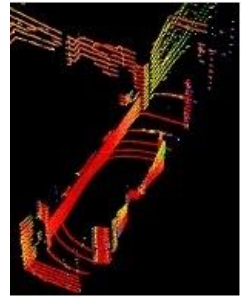

(a)

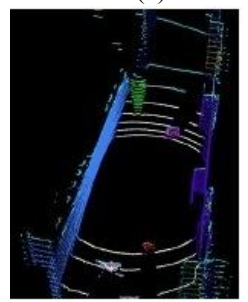

(c)

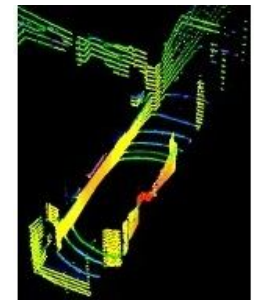

(b)

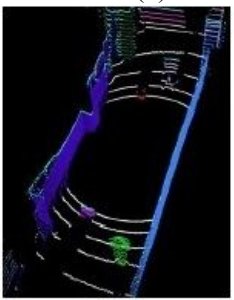

(d)

Fig. 11. Object segmentation for 3-D environmental measurement and reconstruction based on Point Cloud Map using LIDAR for (a) horizontal (b) Vertical (c) Front view, and (d) Rear view distance extraction (Source: Fan et al.) [126]

LIDAR technology was originally applied for outdoor monitoring including meteorological monitoring to measure cloud, airborne and terrain mapping system. Nevertheless, due to the detailed and accurate elevation measurement that the technology provides, it is applied in recent times for 2D/3D indoor applications [127-129].

\section{Techniques for Signal Measurement}

Accurate real-time location identification involves the extraction of location-based information from wireless reference nodes (often term anchor, base station, landmark) deployed at fixed locations, with a mobile node (often term as mobile users, target object or agent) using any of the technologies discussed in the previous Section. Moreover, location identification could imply an opportunistic use of definite methods in estimating the communication between reference nodes and the mobile node [130]. For example, if node $X$ wants to know where node $Y$ is, there are three possibilities: $i$. node $Y$ determines where it is and communicates the location to node $X$ or $i$. as non-cooperative technique where nodes which are randomly deployed, responds to a beacon signal transmitted by node $X$ from several known locations in the field, and iii. a cooperative technique where node $Y$ carries a beacon or RFID tag permitting node $X$ to accurately locate it, thereby allowing each other to determine their location. Fig. 12 highlights a simplified smart home testbed with four reference nodes (RFID readers) and a mobile object (smartphone) attached with an RFID tag for target location.

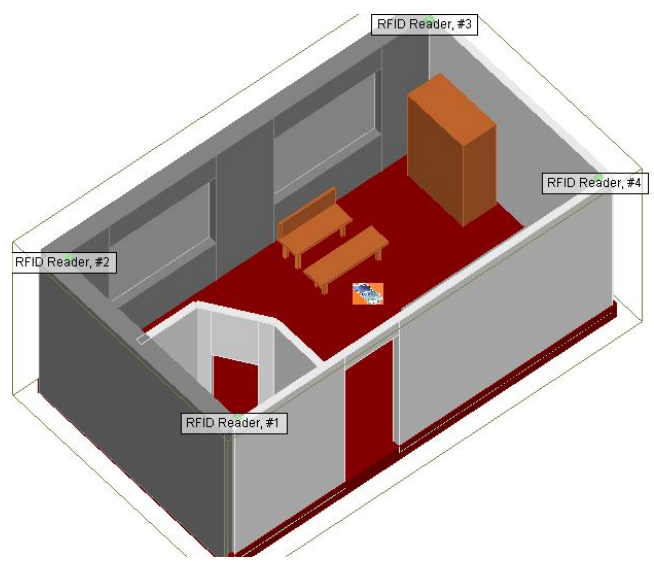

Fig. 12. Simplified testbed for smart home having four reference nodes for target location identification

Location identification techniques based on their applications is either range-based or range-free. Range-based techniques are geometric, and depend on the absolute distance or angle estimated between two or more points whose values are usually a function of the relative position between the reference node and the mobile node. Range-based techniques offer higher accuracy but are often hardware-intensive. Range-based techniques include (a) time-based techniques, such as Time of Arrival (ToA) [131, 132] and Time Difference of Arrival (TDoA) 
[133-135], (b) angle-based techniques, such as Angle of Arrival (AoA) and Direction of Arrival (DoA) [136138], and (c) received signal strength methods [139, 140]. Comparatively, range-free techniques, on the other hand, are dependent on the hops between two or more nodes within a network, so they only use the content of information transmitted [141]. Techniques utilizing this principle include proximity detection [142, 143], V-hop [144] and fingerprinting [145-147]. A summary of the taxonomy of these techniques used for target positioning and other applications is shown in Fig. 13 based on the parameter used in determining target location.

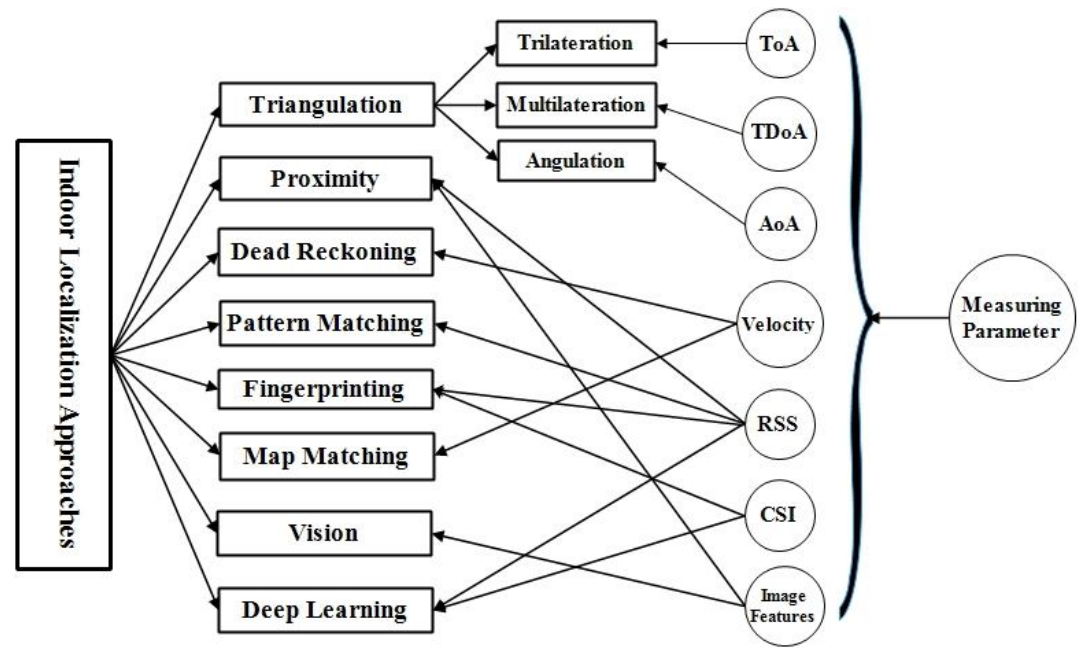

Fig. 13. Taxonomy of location identification techniques

\subsection{Triangulation}

Triangulation utilizes the geometric property of a triangle in localizing target objects and people. Triangulation can be categorized into three techniques since to know where a target is required multiple distance measurements, multiple angle measurements or a combination of angle and distance. These three methods are often referred to as trilateration, multilateration, and angulation, and they involve the measurement of three lengths from a known baseline or measuring two angles from a known baseline and finding their intersection or finding only the angle but then physically follow the signal until the target object is located [148]. Both trilateration and multilateration use the time of propagation of the signal or the received signal strength as a basis of measurement [149, 150], whereas angulation method uses the direction (angle) of the arrival of the mobile signal coming from a predefined location to multiple base station [151]. Triangulation is an effective technique for estimating the location of a wireless device by measuring the distance of the mobile station (MS) to several fixed terminals in determining the position of the mobile target [152].

\subsubsection{Trilateration}

Trilateration is an indoor/outdoor location identification technique, where the MS computes its distance to several BS of known locations using either RSS or ToA of the signal. If the distance is known, a circle with a radius of that distance can be imagined has been around the position of measurement and along the circumference of the circle, which indicates all possible locations of the object. Moreover, for effective 2-D position estimation of an MS or target object, the distance measurement to three BS locations using their ToA is required. Trilateration is also an effective outdoor location identification technique used for GNSS positioning. However, effective trilateration is achieved when the distance of the MS to the BS is synchronized, this condition affects its accuracy since MS - BS distance cannot be computed accurately and easily with models [153].

- Time of Arrival (ToA)

ToA is the travel time between the transmitter and receiver, often measured by the subtraction of the time at which the signal is transmitted from the time the signal reaches the receiver [154]. From Fig 14, it can be seen that ToA can be correlated with the Euclidean distance, derived by the multiplication of the signal travel time by the speed of light. However, the estimation of the Euclidean distance is dependent on the wave speed, which in 
effect is dependent on the properties of the propagation mode and medium, thereby necessitating an accurate understanding of building materials properties [13] and e.g. waveguide modes in corridors. Effective computation using ToA requires the nodes to be synchronized and the time stamp information must be included in the signal [155].

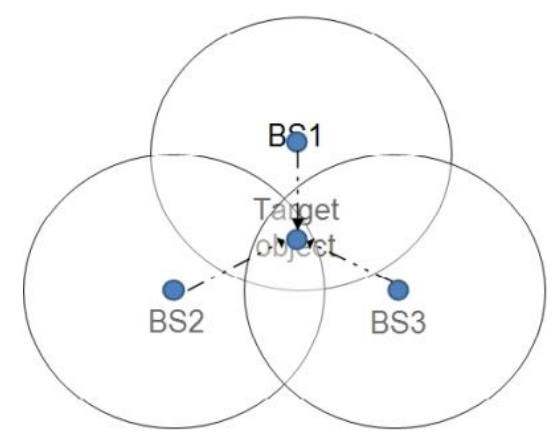

Fig. 14. Time of arrival method

However, accuracy is challenged in environments where multipath effects or interference exist. The need for constant synchronization necessitates the deployment of other time-based techniques such as TDoA and Relative Time of Arrival (RToA) which do not require a common time reference between the nodes [20].

- Time Difference of Arrival-based location identification

Time Difference of Arrival (TDoA) method is based on the time difference at which each RF signal arrives at the receiver from different transmitters [156]. TDoA can be estimated using two approaches; one approach uses the time of arrival of transmitted signal record common to each base station and then subtracting these times over terminal pairs, using the autocorrelation property of the received signal. Another approach is by crosscorrelating the two received signals while their relative timing is adjusted until a peak occurrence is noted [8, 157]. A simplified arrangement of hardware infrastructure used in TDoA method is shown in Fig. 15, where three base stations, $B S_{1}, B S_{2}$ and $B S_{3}$ are used to provide two TDoA measurements $d_{3}-d_{1}, d_{2}-d_{1}$ such that the intersection of these points produces a $2-D$ location of the mobile target.

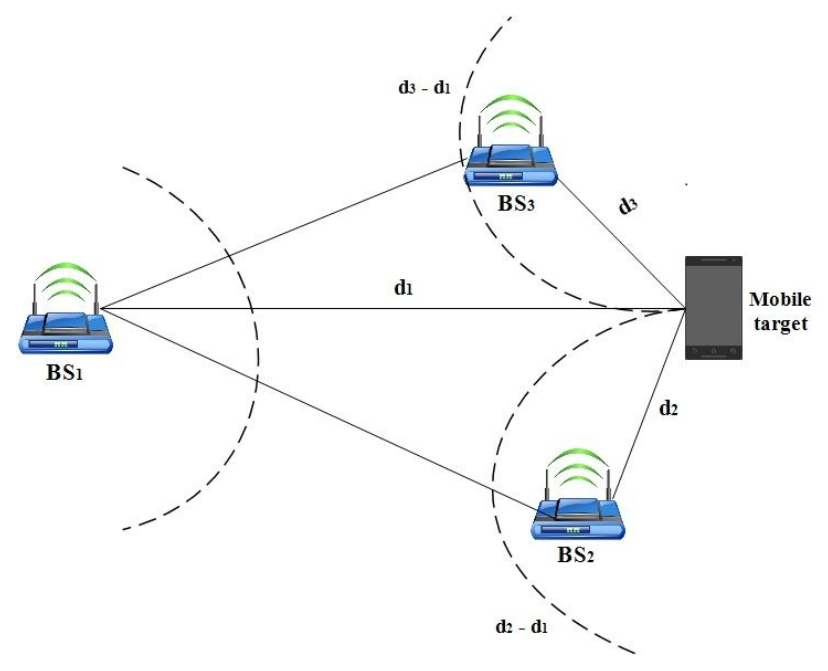

Fig. 15. Time Difference of Arrival Method ${ }^{[158]}$

These approaches require any two receivers at predefined locations to locate a transmitter on a hyperbola at which the signals have the same time difference. The intersection of the hyperbolas formed by the different pair of base stations locates the position of the target object [159]. The conventional TDoA technique which requires 3 or more sensors has been intensely investigated and extended to newer techniques such as Frequency Difference of Arrival (FDoA) [160-162]. One major advantage of TDoA over ToA is that receivers can listen 
passively to the transmitted signal, which invariably locates the position of the transmitter [163], and TDoA does not suffer from the drawback of accurate time synchronization, thereby making it a more effective method $[72,164]$.

- Round Trip Time of Arrival-based location identification

Round Trip Time of Arrival (RToA) overcomes the drawback of accurate time synchronization as required in the ToA method. As shown in Fig. 16, the return trip time of arrival can be measured as the time it takes the transmitted signal to travel from the transmitter to the receiver and return back to the transmitter [165]. However, RToA suffers from latency whenever it is used to measure multiple targets concurrently.

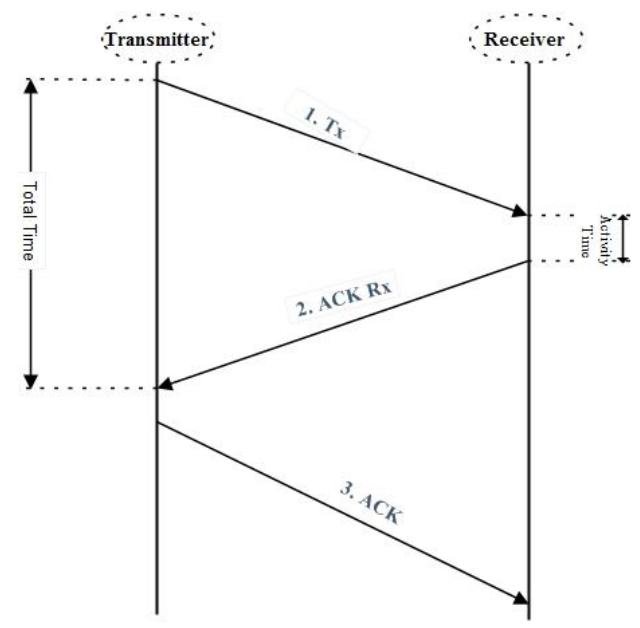

Fig. 16: Round Trip Time of Arrival Method

\subsubsection{Angulation - Angle or Direction of Arrival-based location identification}

Angulation methods use the angle of arrival of the received signal coming from a predefined location to multiple base stations in determining the location of a target object [166]. The typical arrangement of hardware infrastructures for the angulation method is represented in Fig. 17. The direction of angle inclined by the transmitted signal is estimated using the TDoA method at predefined sections of an array of highly directional antennas with the capability of measuring the angle inclined by the transmitted signal [167-169].

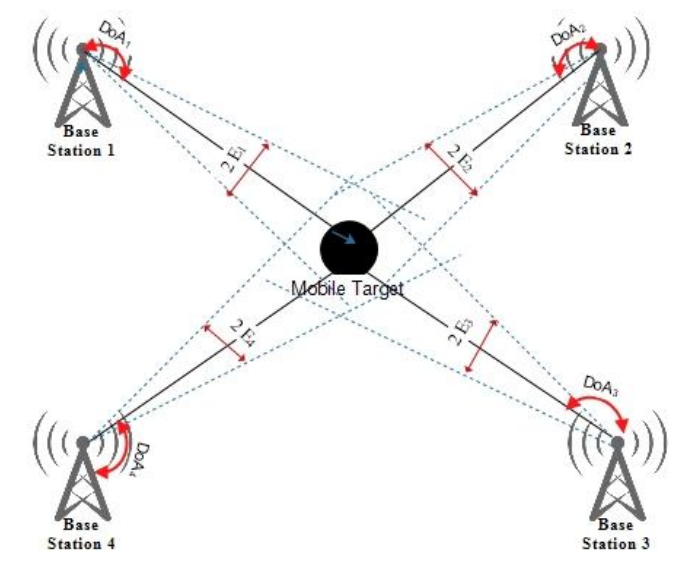

Fig. 17. Angulation method using four anchors and a mobile target

For effective estimation of angles, only two beacons are required for AoA in a 2-dimensional plane, whereas three or more beacons are needed in a 3-dimensional plane. The AoA/DoA method offers higher accuracy when there is LOS, and usually does not require synchronization. However, accuracy using the method is affected by 
several propagation effects such as fading, scattering, reflection, diffraction, shadowing and by the directivity of the antenna [170-174].

\subsection{Proximity-based location identification}

Proximity detection is a location estimation method often based on the relative proximity of the mobile device to predefined known locations as shown in Fig. 18, or it can rely on indirectly inferring the absolute position of the target object [175]. Proximity detection can also be initiated by the sensing environment using computer vision techniques [143], for example using ordinary cameras or Kinect-like depth cameras [176, 177]. More generally, proximity detection is dependent on the dense deployment of antennas in which the sensor nodes are grouped into clusters, and the target location is determined by the Cell of Origin $(\mathrm{CoO})$ method, where a predefined location and limited range is utilized [178, 179]. Moreover, the $\mathrm{CoO}$ will only forward the position of the highest received signal strength to the base station, which is regarded as the most probable target location. Accuracy using proximity detection is related to the density of the beacon points and the signal range. Thus, it is mostly implemented with RF propagation-based technologies such as RFID, Bluetooth, Infrared and custom radio devices [180-183].

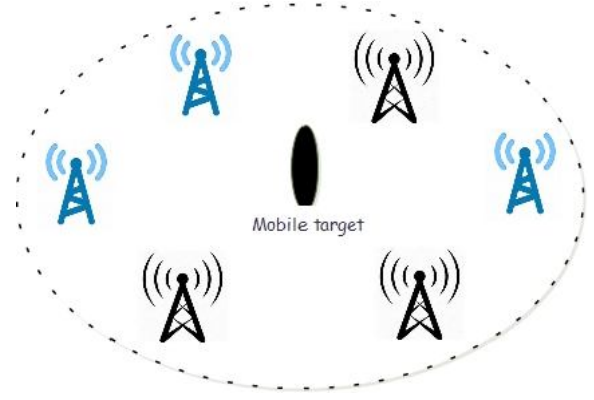

Fig. 18. Proximity Detection Method

Nevertheless, $\mathrm{CoO}$ method is easy and cheap to implement does not involve any complicated algorithms and is suitable for most applications. However, the method is impractical for target identification as it offers low accuracy.

\subsection{RSS and CSI-based location identification}

The RSS method, unlike time-based methods, uses the received signal strength indicator which is on virtually all receivers and to interpret these readings using a dedicated location estimation software [184]. RSS is the average of signals received from different paths at any given location [185], and as such the propagation power loss or attenuation of the transmitted signal is used in estimating the target location. The target location is often estimated using at least three reference points and the corresponding signal attenuation of the signal. The RSSbased method is effective and can be implemented on any existing wireless communication system with almost no hardware changes. However, the method is sensitive to environmental factors such as multipath effects and shadowing [186]. Also, since signal strength attenuates with distance, the accuracy of RSS methods decreases with large distance $[156,187]$, thus it is suitable for short distance application. A significant problem in using RSS as a method for measuring distance is that when an EM signal propagates over a plane earth (rather than in free space) the relationship between signal strength and distance is not single-valued, resulting in ambiguity. However, the RSS-based method suffers from high variability over time for fixed location-aware service due to high multipath effects in the indoor environment, resulting in large location error. In addition, RSS values are often coarse information, therefore the method is often not exploited in the many subcarriers of an orthogonal frequency-division multiplexing (OFDM) systems for improved multipath information. A fallout of the limitations of the RSS-based method is the utilization of channel state information (CSI). CSI estimates the channel through the channel property of communication links such as network interface card (NIC) as the signal propagates between the transmitter and receiver [188]. CSI, therefore, combines the effect of various propagation properties such as fading, scattering and power decay with distance which invariably improves the overall performance of location identification [189, 190]. Nevertheless, CSI in comparison with RSS largely applies different location identification techniques including ToA, AoA, and Fingerprinting [52, 191-193]. 


\subsection{Dead Reckoning}

Dead reckoning estimates an updated position by using the last known location information of the target object. This is achieved by either incrementing the known location based on the velocity of the target object or the known traveled distance $[179,194]$. Dead reckoning utilizes the reading of Inertial measurement unit (IMU) sensors such as gyroscopes, magnetometers, and accelerometers [195-198], thereby making the method independent of external signals [199]. Dead reckoning is relatively simple and efficient in estimating target positions in real time, in comparison with absolute positioning methods [60]. Moreover, hybridization of dead reckoning with absolute positioning updates becomes more efficient using a Kalman filter. However, dead reckoning often suffers from accumulating errors which often necessitates the use of diverse correction methods $[200,201]$.

\subsection{Pattern Matching}

Pattern matching often referred to as scene analysis, utilizes the features of a scene in estimating the location of people or target objects. Pattern matching approach compares the measured data with the closest a priori location data, i.e. positioning of mobile targets is based on the comparison of the actual measurement of ToA or RSS with a radio map, which is a pattern database formed by a set of measurements earlier performed with tags placed at known coordinates. Pattern matching differs slightly from pattern recognition as the latter requires the compared match to be exact, although both methods adopt the fingerprinting approach in localizing target objects. Pattern matching, when used in combination with a neural network, improves location identification in $3 \mathrm{D}$ environments $[202,203]$.

\subsection{Fingerprinting}

Fingerprinting is a database correlation in which the distance between a beacon and transmitting objects is found by comparing the received signal strength pattern with a pre-recorded measurement pattern in the database. Fingerprinting is an efficient location identification approach often applied opportunistically for tracking people and target objects. As shown in Fig. 19, fingerprinting is usually conducted in two distinct phases: an offline (training or survey) phase followed by an online (query, test or positioning) phase [204, 205].

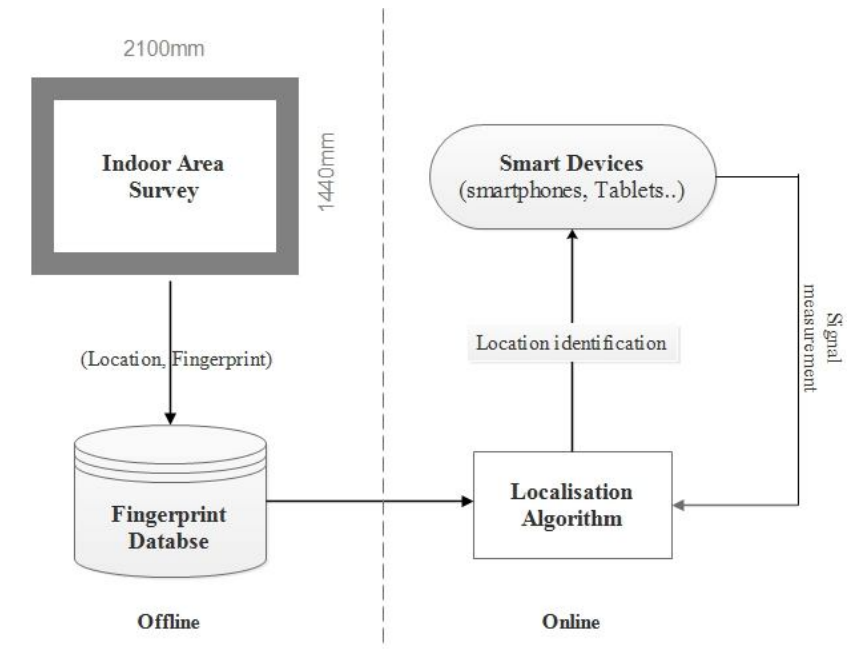

Fig. 19. Distinct phases involved in fingerprinting-based location identification

In the offline phase, signals from each reference node at each training location or site survey are collected by determining the received signal strength indicator (RSSI) and recorded in vectors or radio maps. Each RSSI vector represents the fingerprint of each known training location and is stored in a database for the online query [206]. In the online phase, if a target (user, or mobile device) as shown in Fig 10b samples an RSSI vector at his location and reports it to the server. The location identification algorithm in the server, using some similarity 
metrics, estimates the target location by comparing the vector of the RSSI of the mobile target with the database of the network. The database returns the location with the best correlation with the sent vector [207]. Fingerprinting offer high accuracy with a coverage range of (1-5)m, and effective in the presence of non-line of sight (NLOS) [208], Common algorithms often used for fingerprinting includes (plural) nearest neighbour, probabilistic, neural network, small M-vertex polygon and support vector machine [15]. However, comparison of data often presents a serious location identification challenge in most environments since the signal strength at any fixed location is not always constant. This challenge is overcome by modeling the signal strength using random variables. In addition, fingerprinting becomes inefficient in the offline phase, as it suffers significantly owing to overhead from composing vectors. Thus, efforts are made in developing a more robust algorithm for easy implementation of the technique as found in [209-218].

\subsection{Map Matching-based location identification}

Map matching is an outdoor/indoor location identification approach which involves the process of estimating a continuous target's position on a road network [219]. In general, the concept behind map matching is that the tracking data and mobility models are related to maps. This implies that map matching estimates location from the sampled map information often taken from cameras in accordance to known location parameters to improve the estimation accuracy using various map matching algorithms. In addition, the overall objective of map matching is to increase the accuracy of positioning using the knowledge that the tracked target is restricted in movement or location according to the map [220]. Fig. 20 highlights matching approach using selected key frames acquired from a smartphone camera.

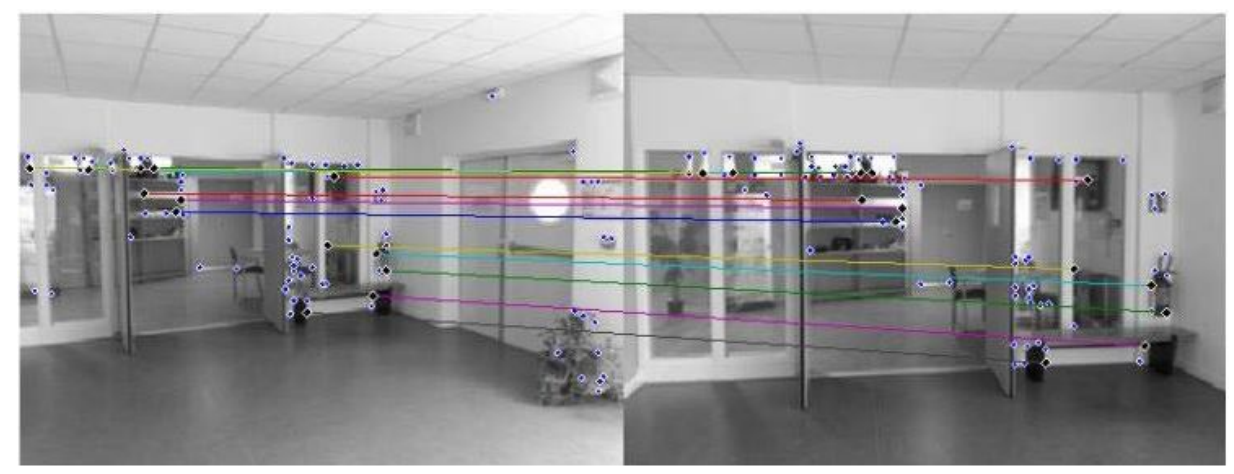

Fig. 20. Map matching approach based on vision using key frames with the highest number of inliers [221]

Map matching approach overcomes the reliability issue associated with proprioceptive sensors used for inertial navigation which often results in their rapidly drifting accuracy with time [222]. Map matching approach utilizes different algorithm approaches which could be: geometric, based on the proximity of the target estimated position to the road network [223, 224]. Probabilistic; where an error region from the error variances associated with the location identification data and road network is derived and overlaid on the road network for identifying the true road segments $[225,226]$. Topological; which compares the geometrical and topological features of the road network with the vehicle trajectory [227, 228], and a more advanced hybridized approach using special decision-making model [229-233]. Nevertheless, the advanced hybridized approach is more reliable and accurate than geometric-based since the approach overcomes all the limitations of geometric-based map matching $[234,235]$.

\subsection{Vision-based location identification}

Vision-based location identification approach is achieved through the utilization of camera sensors. The camera sensor is used to capture visual features and images or to estimate human motion in reference to some features or landmarks that are used as references for determining the image position of the person or object. Furthermore, the vision-based approach also utilizes stored image database annotated with the position information of the cameras. When an image query is received, feature extraction and image matching between the query image and the database images is performed using an efficient algorithm such as the vocabulary tree [236]. Vision-based location identification offers low complexity, as the approach often does not require pre-installation of any 
dedicated infrastructure which serves as a key advantage [221]. However, vision-based location identification suffers from several drawbacks: First, the approach is intrusive in nature resulting in the use of CCD and other low-resolution cameras. Second, the approach becomes unreliable in occlusion situations where objects are blocked by camera detection resulting in low-resolution recognition and poor accuracy [237].

\subsection{Location identification by Deep Learning}

Deep Learning often refers to as hierarchical learning is a dynamic algorithm-based technique used for learning several levels of representation as a means of modeling complex relationships among data [238]. Deep learning offers an effective object recognition and location identification in comparison to the classical machine learning pipeline of feature extraction and classification using a different approach like support vector machine (SVM). Deep learning requires the consistent utilization of object position information which is obtained from the relative posture of the person or the object image regardless of the object distance from the camera for effective object detection and location identification [239]. In addition, the application of Deep Learning using the CSI of NICs for location identification provides an efficient approach to determining the target location. This efficient location identification approach has resulted in the development of several innovative systems like DeepFi, BiLoc, and PhaseFi among others [240-242]. A comparison of these positioning techniques is highlighted in Table 1 with a view to highlighting some of their strengths and weaknesses. High, moderate, low and none are used in classifying the effect of the considered factors on each of the location identification techniques.

Table 1: Comparative summary of indoor techniques for location identification

\begin{tabular}{|c|c|c|c|c|c|c|c|}
\hline Indoor Technique & $\begin{array}{l}\text { Measuring } \\
\text { Parameter }\end{array}$ & Accuracy & Cost & $\begin{array}{l}\text { Energy } \\
\text { Efficiency }\end{array}$ & Complexity & $\begin{array}{l}\text { LOS/ } \\
\text { NLOS }\end{array}$ & $\begin{array}{l}\text { Multipath } \\
\text { Effect? }\end{array}$ \\
\hline \multirow[t]{2}{*}{$\begin{array}{l}\text { Triangulation } \\
\bullet \quad \text { Lateration }\end{array}$} & ToA & High & High & Low & High & LOS & Yes \\
\hline & TDoA & High & Moderate & High & Moderate & LOS & Yes \\
\hline Trilateration & ToA, RSS & High & High & Moderate & High & LOS & Yes \\
\hline - Angulation & AoA & Moderate & High & Moderate & High & LOS & Yes \\
\hline Proximity & RSS & Moderate & Low & High & Moderate & None & No \\
\hline Dead reckoning & Velocity & Moderate & Moderate & High & Low & LOS & Yes \\
\hline Pattern matching & RSS & Moderate & Moderate & Low & Low & None & Yes \\
\hline Fingerprinting & RSS, CSI & High & High & Low & High & NLOS & Yes \\
\hline Map matching & $\begin{array}{l}\text { Velocity, } \\
\text { Acceleration }\end{array}$ & High & High & Moderate & High & LOS & Yes \\
\hline Vision recognition & Video & High & High & Moderate & High & LOS & No \\
\hline Deep Learning & CSI, RSS & High & High & Moderate & High & LOS/NLOS & Yes \\
\hline
\end{tabular}




\section{Formulation of Localisation Problem}

In this section, we formulate a simple location identification problem using ToA and AoA as the location identification techniques for predicting the location and orientation of the target within an indoor environment. Fig. 21 shows a 3-D representation of a target position in an indoor environment having $\mathrm{i}$ anchors. The target motion is defined as a function of time, whilst the target position vector in any of the 3-D Cartesian coordinates at any time instance is a piecewise continuous function of time. The base stations send signals to locate the target such that within an interval, the path described a function of time.

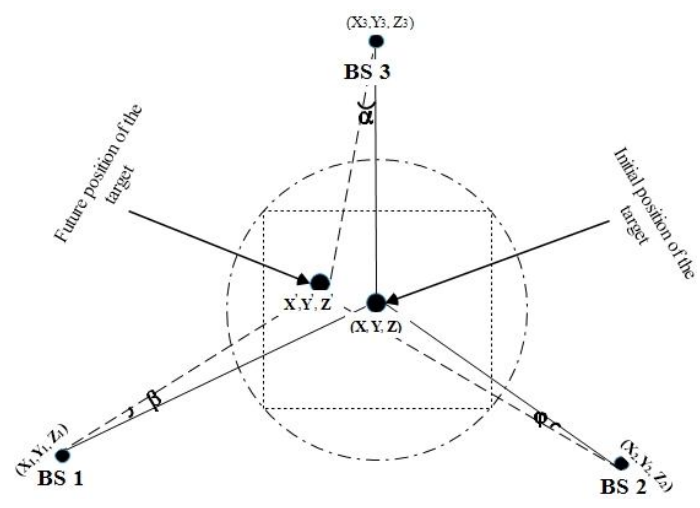

Fig. 21. ToA with three base station.

A curve $\mathrm{C}$ in space can be represented by a vector function represented in Eq. 1

$$
\vec{r}(t)=[x(t), y(t), z(t)]=x(t) i+y(t) j+z(t) k
$$

Going by the above, the location of the anchor in an indoor environment can be represented as $\left(x_{i}, y_{i}, z_{i}\right)$ from

Fig. 21. However, the position vector of the $i^{\text {th }}$ base station can be expressed as:

$$
\vec{r}=\left(x_{i}, y_{i}, z_{i}\right)=x_{i} i^{\prime}+y j^{\prime}+z k^{\prime}
$$

Thus, the location vector of the target with respect to the anchors can be estimated from:

$$
\overrightarrow{r_{a}}=\left(x_{i}-x(t)\right)_{i}+\left(y_{i}-y(t)\right)_{j}+\left(z_{i}-z(t)\right)_{k}
$$

Assume the new (future) location of the target is at $\left[x^{\prime}(t), y^{\prime}(t), z^{\prime}(t)\right]$, then the vector function of the new location can be expressed as:

$$
\vec{r}(t)=\left[x^{\prime}(t), y^{\prime}(t), z^{\prime \prime}(t)\right]=x^{\prime}(t)_{i}+y^{\prime}(t)_{j}+z^{\prime \prime}(t)_{k}
$$

Therefore, the position vector of the new location will be given as:

$$
\overrightarrow{r_{f p}}(t)=\left[x_{i}-x^{\prime}(t)\right] i+\left[y_{i}-y^{\prime}(t)\right] j+\left[z_{i}-z^{\prime}(t)\right]
$$

Algebraically, rewriting Eq. (5) as $d_{i}$, which represents the distance between base station and target. Therefore,

$$
\begin{gathered}
d_{i}=\sqrt{\left(x_{i}-x(t)\right)^{2}+\left(y_{i}-y(t)\right)^{2}+\left(z_{i}-z(t)\right)^{2}} \\
d_{i}^{\prime}=\sqrt{\left(x_{i}-x^{\prime}(t)\right)^{2}+\left(y_{i}-y^{\prime}(t)\right)^{2}+\left(z_{i}-z^{\prime}(t)\right)^{2}}
\end{gathered}
$$

Using the cosine rule, the distance between the anchors and the target position can be estimated from:

$$
d_{i}=d_{i}^{\prime} \cos \phi_{i} \pm \sqrt{d_{i}^{\prime} \cos ^{2} \phi_{i}+4\left(k_{i}^{2}-d_{2}^{\prime 2}\right)}
$$

where $\phi_{i}=\alpha, \beta, \gamma$ as shown in Fig. 21 and $k$ represents the distance between the initial and present location of the target in a coordinate of interest.

\subsection{Modelling the look angle of the reference node}

In sensor location identification, an opportunistic use of the look angle is critical in obtaining an accurate location and orientation position of the target. Fig. 22 shows the formation of the Look angle, as the angle formed by the two angles of the inclination $(\theta, \varphi)$ of the $B S . \theta$ represents the angle a sensor makes with $x(t)$ 
axis measured in the horizontal $(x, y)$ plane, whilst $\varphi$ is the angle of inclination of the sensor to the horizontal $(x, y)$ plane as measured from the vertical $(z, \in)$ plane. Here, $(\theta, \varphi)$ is estimated by drawing a straight line from the position of the sensor to the predicted coordinate location of the intercept which indicates the location of the target. In addition, $(\theta, \varphi)$ also describe the orientation of the sensors in that signals are aimed at the direction of the target location at a future time $t_{n}$.

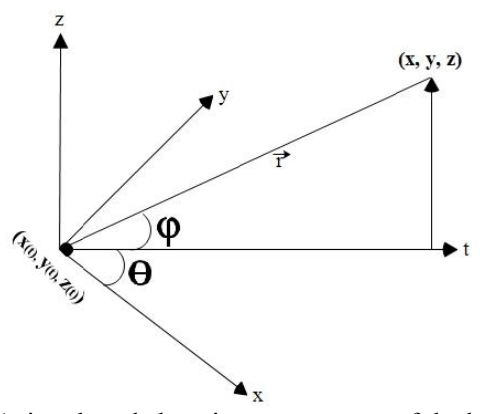

Fig. 22. Azimuth and elevation components of the look angle

If $x, y, z$ axes at $t$ are defined as shown in Fig. 22, then the angle of inclination, $\varphi$, in the $z, t$ plane can be expressed as:

$$
\varphi=\tan ^{-1} \frac{z-z(t)}{\sqrt{(x-x(t))^{2}+(y-y(t))^{2}}}
$$

Here, the denominator in Eq. (9) gives the magnitude of $\vec{r}_{t F}$ in the direction $t$, whilst the angle $\theta$ in the $\mathrm{x}$-y direction can be expressed as:

$$
\theta=\tan ^{-1}\left(\frac{y-y(t)}{x-x(t)}\right)
$$

Referring to Fig. 21, the target new position $k_{i}$ can be estimated. Therefore, by applying the cosine formula, the position of the target orientation can be obtained, i.e.

where

$$
k_{i}=d_{i}^{2}+d_{i}^{2}-2 d_{i} d_{i}^{\prime} \cos \phi_{i}
$$

$$
\phi_{i}=\beta, \alpha, \gamma
$$

Thus, the new position of the target orientation with respect to $d_{i}$ can be estimated from Fig. 23 .

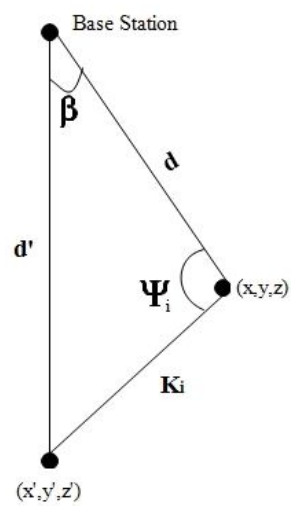

Fig. 23. Determination of target orientation using AoA

Also, applying sine rule,

and rearranging Eq. (13) gives

$$
\frac{d_{i}^{\prime}}{\sin \psi_{i}}=\frac{k_{i}}{\sin \phi_{i}}
$$




$$
\begin{array}{r}
\sin \psi_{i}=\frac{d_{i}^{\prime} \sin \phi_{i}}{k_{i}} \\
\psi_{i}=\sin ^{-1}\left(\frac{d_{i}^{\prime} \sin \phi_{i}}{k_{i}}\right) \\
\psi_{i}(t)=\sin ^{-1}\left(\frac{d_{i}(t) \sin \phi_{i}(t)}{k(t)}\right)
\end{array}
$$

\section{Selection Metrics for RF-Based Location Identification}

In this section, we shall focus on the performance of RF-based location identification technologies using a common generic metric of scalability, accuracy, complexity, robustness, reliability, energy efficiency, cost, and throughput. The metrics are used for the empirical evaluation of each indoor technology with a view to establish the viability of each RF-based technologies.

\subsection{Scalability}

Scalability describes the adaptive ability of a location identification system to allow many instances of the technology to operate independently without interfering with each other, while at the same time the system stability is still maintained [243]. Scalability is a critical factor that guarantees the overall performance of location identification systems since the number of cooperating small-scale, low-powered nodes with limited sensing and computational capability may often need to be replaced or increased. However, location identification efficiency degrades with an increase in distance between the nodes and the receiver, which usually require most techniques used to be modified. To modify the system to make it more scalable, recent location identification techniques scale the target on two axes i.e. the density and the geography.

\subsection{Accuracy}

Accuracy gives the degree of deviation of the estimated position from the actual position, i.e. it is the closest calculated position to the true position without a prior knowledge of the target known location often termed location identification error. Location identification error refers to the measurement that gives the average Euclidean distance between the estimated location and the true location. Thus, since obtaining accurate information of a target location is the primary objective of any location identification system, accuracy can be improved through joint detection and estimation of the sensor nodes.

\subsection{Precision}

Precision is an indication of the repeatability of a measurement. Precision is a sensitivity-based performance metric that determines the reliability of a location identification system in presence of changing environmental conditions. Precision is often used interchangeably as resolution in much location identification literature. However, precision and accuracy are closely related, as precision relates to the deviation of the distance error, whilst accuracy relates to the mean of the distance error. Therefore, an accurate location identification system might not necessarily be precise, but a precise location identification system will have high accuracy. Nevertheless, the precision of most location identification systems is often around $5-20 \mathrm{~cm}$.

\subsection{Complexity}

The complexity of location identification systems can be described as the degree of hardware, software and operating factors applied to the overall system. Complexity is often more difficult to support when there is no power. It is, however, less of a problem when the algorithm used for location identification runs on a server with a power supply. However, it can be challenging when the platform running the algorithm is mobile where strong processing power and durable power supply can affect the reliability of the system. Thus, location rate estimates the delay between the mobile target reaching the new location and the time of estimation of the new location. 


\subsection{Robustness}

Location identification systems often face the challenge of one or more failing components within the network. In addition, factors such as the complexity of the indoor environments and other physical effects often do present the location identification system with incomplete data to localize a target, which affects the system performance. Thus, robustness describes the ability of location identification systems to continue to provide reliable and accurate measurements even when conditions are adverse, e.g. in the presence of interfering sources or many targets co-located.

\subsection{Reliability}

Reliability is a crucial performance metric as it measures the percentage of measurements for which the accuracy meets some threshold. This is because a system might sometimes give an accurate measurement and at other times give no measurement or an inaccurate one. Thus, reliability indicates the level of dependability of the overall system.

\subsection{Energy Efficiency}

Location identification applications often do require reasonable longevity, and since most sensor nodes are likely to be battery-powered. Charging or recharging of these batteries for the nodes is not usually feasible in many applications [244], thus an aggressive energy management policy is crucial for these battery-powered nodes [245]. Moreover, energy efficiency in sensor-based applications is affected by environmental factors resulting from collision, overhearing and idle listening and control packet overhead. Therefore, energy efficiency in most indoor applications is considered one of the current design challenges and a critical performance metric.

\subsection{Cost}

Cost divides between the various hardware infrastructures (beacons, servers, tags) used in a location identification system, which can be evaluated in several diverse ways such as roll-out, operating/maintenance, and space cost. Roll-out costs involve the cost required in either installing the new hardware infrastructures or extending the existing infrastructure. Operating or maintenance costs are cost involved in maintaining the optimal functionality of a location identification system, thereby reducing the overall complexity of the system [3]. Space cost relates to the number and size of the hardware infrastructure. Thus, overall cost trade-offs will depend on how many hardware infrastructures are deployed. In addition, system complexity will increase cost and invariably increase its complexity. Hence cost in a relatively small number of servers etc. so that cost of tags can be reduced may lead to overall cost reduction where there are many tags and few servers.

\subsection{Throughput}

Throughput describes the number of successful messages delivered per unit time. Indoor applications using different technologies exhibit throughput specific to the technology. For example, a fingerprinting system using Wi-Fi can keep track of 100 targets spread over a spatial area of $1000 \mathrm{~m}^{2}$ within an RMS position error of $2 \mathrm{~m}$. The RFID system, on the other hand, can identify up to 400 separate targets within a $1 \mathrm{~m}$ range and takes 1 second to reliably register changes in the population of targets in its captured range. Therefore, in this survey, we assume all indoor technology possess reliable throughput.

Table 2: Empirical Assessment Scale

\begin{tabular}{|c|c|}
\hline Assessment & Score \\
\hline Excellent & 5 \\
\hline High & 4 \\
\hline Moderate & 3 \\
\hline Low & 2 \\
\hline Extremely Low & 1 \\
\hline
\end{tabular}

Table 3. Empirical evaluation of RF-based indoor technologies 


\begin{tabular}{|c|c|c|c|c|c|c|c|c|}
\hline Performance Metric & 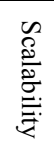 & 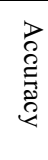 & 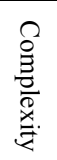 & 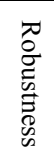 & 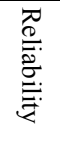 & 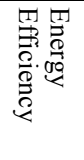 & 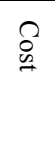 & 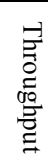 \\
\hline Magnetic-based [246-252] & 2 & 3 & 4 & 2 & 3 & 4 & 4 & 4 \\
\hline Ultrasound [253-255] & 3 & 3 & 4 & 2 & 3 & 4 & 3 & 4 \\
\hline Infrared $[254,256-258]$ & 3 & 2 & 3 & 2 & 2 & 2 & 3 & 4 \\
\hline Bluetooth $[82,259,260]$ & 4 & 4 & 2 & 2 & 4 & 2 & 2 & 4 \\
\hline Wi-Fi [73, 260-262] & 4 & 4 & 4 & 4 & 3 & 2 & 4 & 4 \\
\hline ZigBee [263-266] & 3 & 4 & 2 & 4 & 3 & 4 & 4 & 4 \\
\hline UWB $[106,112,113,267,268]$ & 5 & 4 & 2 & 2 & 3 & 2 & 3 & 4 \\
\hline RFID $[2,42,269-273]$ & 5 & 4 & 4 & 4 & 4 & 5 & 5 & 4 \\
\hline
\end{tabular}

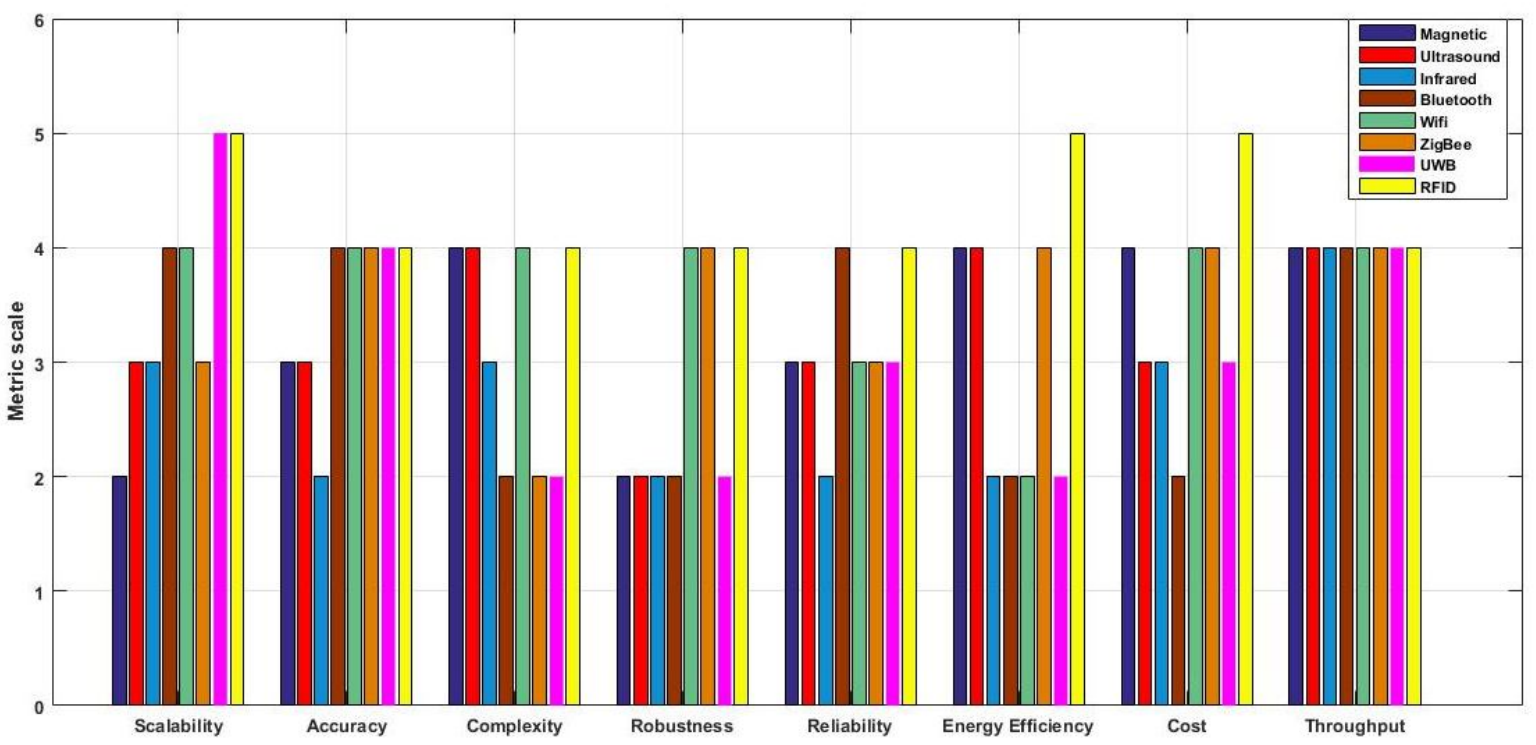

Fig. 24. Comparative evaluation of some location identification technologies 
Table 4: Overview of various RF-based location identification systems using a common metric of performance ${ }^{3}$

\begin{tabular}{|c|c|c|c|c|c|c|c|c|c|c|}
\hline $\begin{array}{l}\text { Common indoor technologies and } \\
\text { established existing systems }\end{array}$ & 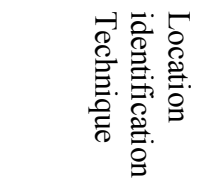 & 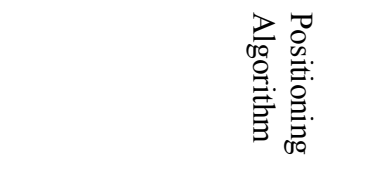 & 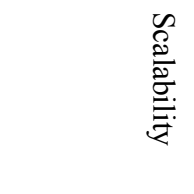 & 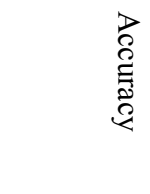 & 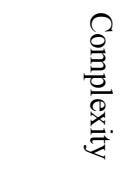 & 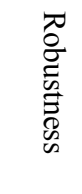 & 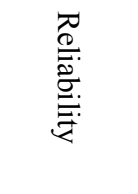 & 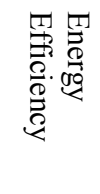 & $\underset{8}{0}$ & 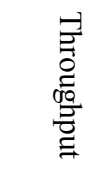 \\
\hline $\begin{array}{l}\text { Ultrasound } \\
\text { Smart LOCUS [274] } \\
\text { TELIAMADE [275] } \\
\text { CRICKET [276] } \\
\text { Active Badge [277] }\end{array}$ & AoA, ToA, ToF & $\begin{array}{l}\text { Genetic Algorithm, Distributed } \\
\text { Listener Inference, Outliner } \\
\text { Rejection }\end{array}$ & Poor, 3D & 0.01 to $1 \mathrm{~m}$ & High & Low & Moderate & High & Moderate & High \\
\hline $\begin{array}{l}\text { Infrared } \\
\text { Active Badge [277] } \\
\text { Firefly [278] } \\
\text { OPTOTRAK [279] } \\
\text { EIRIS [280] } \\
\text { IRIS_LPS [281] }\end{array}$ & ToA, Proximity & $\begin{array}{l}\text { Genetic Algorithm, } \\
\text { Ray-tracing, } \\
\text { Angle adaptation }\end{array}$ & Poor, 3D & 1 to $2 \mathrm{~m}$ & Moderate & Low & Low & Low & Moderate & High \\
\hline $\begin{array}{l}\text { Bluetooth } \\
\text { TOPAZ [282] } \\
\text { ZONITH [283] } \\
\text { Apple iBeacon [284] }\end{array}$ & RSSI & Extended Kalman Filter & Good, 3D & 2 to $5 \mathrm{~m}$ & Low & Low & High & Low & Low & High \\
\hline $\begin{array}{l}\text { Wi-Fi } \\
\text { RADAR [35, 285] } \\
\text { Ekahau [286] }\end{array}$ & $\begin{array}{l}\text { ToA, TDoA, } \\
\text { Fingerprint }\end{array}$ & $\begin{array}{l}\text { KNN, Bayesian Approach, } \\
\text { Probabilistic method }\end{array}$ & Good, 2D, 3D & & & & & & & \\
\hline $\begin{array}{l}\text { Horus [287, 288] } \\
\text { SmartCampusAAU [289] } \\
\text { Nibble [290] } \\
\text { WhereMops [291] }\end{array}$ & & & & 1 to $5 \mathrm{~m}$ & High & High & Fair & Low & High & High \\
\hline $\begin{array}{l}\text { ZigBee } \\
\text { CC2431 [292] } \\
\text { ZigBEACON [293] }\end{array}$ & $\begin{array}{l}\text { RSSI, TDoA, } \\
\text { ToA, AoA, } \\
\text { Fingerprint }\end{array}$ & Signal Propagation Exponent & Moderate & 3 to $5 \mathrm{~m}$ & Low & High & Fair & High & High & High \\
\hline $\begin{array}{l}\text { UWB } \\
\text { Sapphire Dart [294] } \\
\text { Zebra Dart UWB [295] }\end{array}$ & $\begin{array}{l}\text { RSSI - } \\
\text { Fingerprint }\end{array}$ & Least Square & $\begin{array}{l}\text { Excellent 2D, } \\
\text { 3D }\end{array}$ & & & & & & & \\
\hline $\begin{array}{l}\text { Ubisense [296] } \\
\text { Decawave Scensor [297] }\end{array}$ & TDOA, ToA & & & $\geq 10 \mathrm{~cm}$ & Low & Low & Fair & Low & Low & High \\
\hline
\end{tabular}

${ }^{3}$ Table 4 is based on the author's opinion as established in the literature. 
RFID

LANDMARC [298]

SpotON [299]

Proximity, ToA, KNN

RSSI

Excellent

1 to $5 \mathrm{~m}$

Low

High High

2D, 3D 
Table 5: Existing and proposed indoor hybrid systems for reliable IoT-based location identification

\begin{tabular}{|c|c|c|c|c|c|c|c|c|c|c|c|c|}
\hline $\begin{array}{l}\text { Existing and proposed } \\
\text { Hybridized location } \\
\text { identification systems }\end{array}$ & 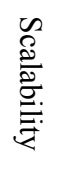 & 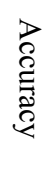 & 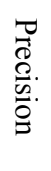 & 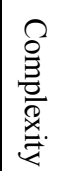 & 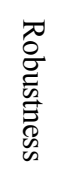 & 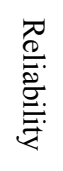 & 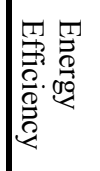 & 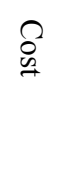 & 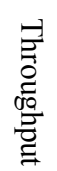 & Feasible points for hybridization & Possible challenges and drawbacks & Possible areas of applications \\
\hline $\begin{array}{l}\text { INS }+ \text { Wi-Fi }+ \\
\text { Fingerprinting [302- } \\
\text { 304] }\end{array}$ & $\sqrt{ }$ & & & $\sqrt{ }$ & $\sqrt{ }$ & $\sqrt{ }$ & $\sqrt{ }$ & & & $\begin{array}{l}\text { Since RSS measurement can be used for } \\
\text { both technologies, where a database of } \\
\text { vector map of the field strengths can be } \\
\text { constructed and accessed even outdoors. } \\
\text { Thus, longer detection range and high } \\
\text { accuracy can be achieved. }\end{array}$ & $\begin{array}{l}\text { Mapping of RSSI must be done with an in- } \\
\text { depth accuracy. The approach could face } \\
\text { accumulated error over time. External } \\
\text { references or human input is required }\end{array}$ & $\begin{array}{l}\text { Multimodal transportation network, } \\
\text { Pedestrian navigation, Activity } \\
\text { recognition }\end{array}$ \\
\hline INS + RFID [305] & $\sqrt{ }$ & $\sqrt{ }$ & & & $\sqrt{ }$ & & $\sqrt{ }$ & $\sqrt{ }$ & $\sqrt{ }$ & High range, Cheap, & $\begin{array}{l}\text { The requirement for system parts that supports } \\
\text { high precision tolerance. Complex assembly } \\
\text { technique. Obtrusive. Constant recalibration is } \\
\text { required. Computational processing, }\end{array}$ & $\begin{array}{l}\text { Vehicular positioning, Healthcare, } \\
\text { Aircraft, Missile Defence System, } \\
\text { Animal and Human motion }\end{array}$ \\
\hline $\begin{array}{l}\text { INS + Bluetooth + } \\
\text { ToA/TDoA/AoA } \\
{[306]}\end{array}$ & $\sqrt{ }$ & $\sqrt{ }$ & & $\sqrt{ }$ & & $\sqrt{ }$ & & $\sqrt{ }$ & $\sqrt{ }$ & $\begin{array}{l}\text { No user input is required, as the user will } \\
\text { provide input passively. }\end{array}$ & $\begin{array}{l}\text { Constant recalibration is required. Inaccurate } \\
\text { results are highly possible due to errors in } \\
\text { measurement }\end{array}$ & Robot and Vehicular navigation \\
\hline $\mathrm{INS}+\mathrm{UWB}$ & & $\sqrt{ }$ & & & $\sqrt{ }$ & $\sqrt{ }$ & & $\sqrt{ }$ & $\sqrt{ }$ & Improved accuracy over $150 \mathrm{~m}$ & & Vehicular navigation, tracking \\
\hline $\begin{array}{l}\text { RFID + UWB + ToA } \\
{[307]}\end{array}$ & $\sqrt{ }$ & $\sqrt{ }$ & & $\sqrt{ }$ & & $\sqrt{ }$ & $\sqrt{ }$ & $\sqrt{ }$ & $\sqrt{ }$ & $\begin{array}{l}\text { High detection range and signal transfer } \\
\text { due to large bandwidth, which can satisfy } \\
\text { most of the multimedia applications. }\end{array}$ & Interference and Clock Drift & $\begin{array}{l}\text { Precision asset location, digital } \\
\text { homes, Multimedia applications }\end{array}$ \\
\hline $\begin{array}{l}\text { UWB + Ultrasound + } \\
\text { Fingerprinting }\end{array}$ & $\sqrt{ }$ & $\sqrt{ }$ & & & $\sqrt{ }$ & $\sqrt{ }$ & $\sqrt{ }$ & $\sqrt{ }$ & & $\begin{array}{l}\text { Both require wideband for higher } \\
\text { efficiency, }\end{array}$ & $\begin{array}{l}\text { Severe noise sensitivity, Complexity hardware, } \\
\text { and computational power is required }\end{array}$ & Medical Imaging \\
\hline $\begin{array}{l}\text { RFID + Ultrasound }+ \\
\text { ToA or TDoA [308] }\end{array}$ & & $\sqrt{ }$ & & $\sqrt{ }$ & & $\sqrt{ }$ & & $\sqrt{ }$ & $\sqrt{ }$ & $\begin{array}{l}\text { Low cost, robust in the presence of } \\
\text { multipath. Higher capacity reduced } \\
\text { exposure of the user to ultrasound due to } \\
\text { the non-wearable ultrasound transmitter }\end{array}$ & $\begin{array}{l}\text { Effective read range requirement for high } \\
\text { accuracy. Low robustness due to external noise }\end{array}$ & $\begin{array}{l}\text { Robot navigation, indoor } \\
\text { positioning of stationary target } \\
\text { objects }\end{array}$ \\
\hline Bluetooth + ZigBee & $\sqrt{ }$ & $\sqrt{ }$ & & $\sqrt{ }$ & & $\sqrt{ }$ & & & $\sqrt{ }$ & $\begin{array}{l}\text { Higher flexibility and reliability in } \\
\text { various dimension and mesh network } \\
\text { architectures. Longer energy } \\
\text { management. }\end{array}$ & $\begin{array}{l}\text { Poor energy management, interference from } \\
\text { collisions, }\end{array}$ & Industrial wireless communication; \\
\hline RFID + ZigBee & $\sqrt{ }$ & $\sqrt{ }$ & & & $\sqrt{ }$ & $\sqrt{ }$ & $\sqrt{ }$ & & $\sqrt{ }$ & $\begin{array}{l}\text { Robust system with support for more } \\
\text { advanced mesh network application and } \\
\text { high capability. Computational } \\
\text { effectiveness. Improved performance and } \\
\text { reliability. }\end{array}$ & The requirement of multiple receivers, & $\begin{array}{l}\text { Healthcare, Home Automation, } \\
\text { Inventory tracking }\end{array}$ \\
\hline ZigBee + Bluetooth + & & & & & & & & & & Similar operating frequency, high & Increased interference from multipath which & Home Automation for smart home \\
\hline
\end{tabular}




\begin{tabular}{|l|l|l|l|l|l|l|l|l|l|l|l|l|}
\hline Wi-Fi & $\sqrt{ }$ & $\sqrt{ }$ & & $\sqrt{ }$ & $\sqrt{ }$ & $\sqrt{ }$ & $\sqrt{ }$ & & $\sqrt{ }$ & $\begin{array}{l}\text { throughput, supported by most mobile } \\
\text { devices, wider coverage area and range }\end{array}$ & can be delimited by ZigBee \\
\hline $\begin{array}{l}\text { ZigBee +Wi-Fi }+ \\
\text { Fingerprinting }\end{array}$ & & $\sqrt{ }$ & & $\sqrt{ }$ & & $\sqrt{ }$ & $\sqrt{ }$ & $\sqrt{ }$ & $\sqrt{ }$ & $\begin{array}{l}\text { High throughput, high energy efficiency, } \\
\text { improved accuracy }\end{array}$ & RF congestion resulting in energy consumption & Home Automation \\
\hline
\end{tabular}




\section{Discussion}

To compare the RF-based technologies, we develop an assessment scoring scale as presented in Table 2. Table 2 is used in generating Table 3, which presents our empirical evaluation of each sampled RF-based technologies based on established assessments in the literature. It is noteworthy to state that under complexity and cost metric, the scoring system is reversed since the lower the metric, the higher its effect on the overall performance of each indoor systems. However, from Table 4, we present an overview of each RF-based technologies and their equivalent commercially available systems. A graphical representation of the performance of each RFbased technology based on our evaluation is illustrated in Fig 24, where it can be observed that none of these technologies can satisfy the performance requirements of any location identification application since each technology exhibits certain limitations. However, in our opinion, Wi-Fi, RFID, UWB, Wi-Fi, Bluetooth, ZigBee shows higher viability over most other technologies due to their exceptional advantage of cognitive intelligence, compatibility with most devices, higher precision, low EM radiation, large bandwidth, high penetrating power, lower and effective coverage area exhibited in applications.

A combination of two or more of these technologies (hybridization) will, therefore, enhance the accuracy standard requisite by international authorities for most indoor applications especially in the extreme context of enhanced emergency services. Table 5, therefore, highlights some existing and proposed hybridized indoor system with their expected characteristics.

Hence, we advocate increased hybridization of technologies as an effective approach to achieving reliable IoTbased indoor systems. Although the advantages of hybridization are being exploited by different authors, who have "navigated" their research interest towards this direction [309-322], however, an increased exploitation of hybridization would raise the bar toward attaining a more robust, reliable IoT-based indoor applications and systems.

\section{Conclusion}

In this work, an inclusive survey on indoor location identification methods, underlying principles, deployment approach technologies and techniques. The survey highlight the complexity of the indoor environment due to the propagation of different signals often propagated within it resulting in the unreliability of the outdoor systems. In addition, since most people usually expend a considerable amount of time daily within various indoor environments for different purposes, location identification becomes an interesting research area for safety and emergency measures. The empirical evaluation of RF-based technologies in this study highlights the viability of Wi-Fi, RFID, UWB, Wi-Fi, Bluetooth, ZigBee, and optical technologies. However, since each of these technologies exhibits one form of limitation or another due to their operating parameters. Therefore, we advocate for the combination of different technologies to leverage their limitation and improve the overall performance of developed hybridized systems.

\section{Acknowledgment}

This work is supported in part by the Tertiary Education Trust Fund of Federal Government of Nigeria, and in part by the European Union's Horizon 2020 Research and Innovation Programme under the Grant agreement H2020-MSCA-ITN-2016 SECRET-722424.

\section{References}

[1] I. Ahmad, R. Asif, R. A. Abd-Alhameed, H. Alhassan, F. Elmegri, J. M. Noras, et al., "Current technologies and location-based services," in 2017 Internet Technologies and Applications (ITA), 2017, pp. 299-304.

[2] T. Sanpechuda and L. Kovavisaruch, "A review of RFID localization: Applications and techniques," in Electrical Engineering/Electronics, Computer, Telecommunications and Information Technology, 2008. ECTI-CON 2008. 5th International Conference on, 2008, pp. 769-772.

[3] A. Kupper, Location-Based Services: Fundamentals and Operation. England: John Wiley \& Sons, Ltd, 2005.

[4] K. Saleem, A. Derhab, M. A. Orgun, and J. Al-Muhtadi, "Analysis of the Scalability and Stability of an ACO Based Routing Protocol for Wireless Sensor Networks," pp. 234-239, 2015.

[5] J. Vongkulbhisal and Z. Yan, "An RFID-based indoor localization system using antenna beam scanning," in Electrical Engineering/Electronics, Computer, Telecommunications and Information Technology (ECTI-CON), 2012 9th International Conference on, 2012, pp. 1-4. 
[6] C. L. Allan Brimicombe, Location-Based Services and Geo-Information Engineering. Sussex, UK: Wiley-Blackwell, 2009.

[7] R. Mautz, "Indoor Positioning Technologies", Ph.D. thesis, Department of Civil, Environment and Geomatic Engineering, ETH Zurich, Zurich, 2012.

[8] A. Bensky, Wireless Positioning Technologies and Applications. Boston, London: ARTECH HOUSE, INC., 2008.

[9] Z. Farid, R. Nordin, and M. Ismail, "Recent Advances in Wireless Indoor Localization Techniques and System," Journal of Computer Networks and Communications, vol. 2013, pp. 1-12, 2013.

[10] S. Adler, S. Schmitt, and M. Kyas, "Path loss and multipath effects in a real-world indoor localization scenario," in Positioning, Navigation and Communication (WPNC), 2014 11th Workshop on, 2014, pp. $1-7$.

[11] S. Schmitt, S. Adler, and M. Kyas, "The effects of human body shadowing in RF-based indoor localization," in Indoor Positioning and Indoor Navigation (IPIN), 2014 International Conference on, 2014, pp. 307-313.

[12] N. A. Alrajeh, M. Bashir, and B. Shams, "Localization Techniques in Wireless Sensor Networks," International Journal of Distributed Sensor Networks, vol. 2013, pp. 1-9, 2013.

[13] R. Mautz, "The challenges of indoor environments and specification on some alternative positioning systems," in Positioning, Navigation and Communication, 2009. WPNC 2009. 6th Workshop on, 2009, pp. 29-36.

[14] Y. Gu, A. Lo, and I. Niemegeers, "A survey of indoor positioning systems for wireless personal networks," IEEE Communications Surveys \& Tutorials, vol. 11, pp. 13-32, 2009.

[15] L. Hui, H. Darabi, P. Banerjee, and L. Jing, "Survey of Wireless Indoor Positioning Techniques and Systems," Systems, Man, and Cybernetics, Part C: Applications and Reviews, IEEE Transactions on, vol. 37, pp. 1067-1080, 2007.

[16] H. K. Klaithem A, "A Survey of Indoor Positioning and Object Locating Systems and Algorithm," presented at the International Conference on Innovations in Information Technology, 2011.

[17] Z. Da, X. Feng, Y. Zhuo, Y. Lin, and Z. Wenhong, "Localization Technologies for Indoor Human Tracking," in Future Information Technology (FutureTech), 2010 5th International Conference on, 2010, pp. 1-6.

[18] S. H. Y. H. Koyuncu, "A Survey of Indoor Positioning and Object Locating Systems," International Journal of Computer Science and Network Security, vol. 10, May 20102010.

[19] D. Dardari, P. Closas, and P. M. Djuric, "Indoor Tracking: Theory, Methods, and Technologies," Vehicular Technology, IEEE Transactions on, vol. 64, pp. 1263-1278, 2015.

[20] L. Brás, N. B. Carvalho, P. Pinho, L. Kulas, and K. Nyka, "A Review of Antennas for Indoor Positioning Systems," International Journal of Antennas and Propagation, vol. 2012, 2012.

[21] G. Kitagawa, "Monte Carlo Filter and Smoother for Non-Gaussian Nonlinear State Space Models," Journal of Computational and Graphical Statistics, vol. 5, pp. 1-25, 1996/03/01 1996.

[22] Youseff, Hadhri, and Maherzi, "Determinants of the Adoption of Cloud Computing by Tunisian Firms: An Exploratory Study," presented at the International Conference of Data Digital Business Models, Cloud Computing and Organizational Design, Paris, France, 2014.

[23] O. Abouelkhair and A. Elsaadany, "Hierarchal Energy Efficient Network Protocol for wireless sensing," in Computer Engineering Conference (ICENCO), 2014 10th International, 2014, pp. 128132.

[24] C. D. McGillem and T. S. Rappaport, "Infra-red location system for navigation of autonomous vehicles," in Robotics and Automation, 1988. Proceedings., 1988 IEEE International Conference on, 1988, pp. 1236-1238 vol.2.

[25] C. H. A. Günther, Measuring Round Trip Times to Determine the Distance Between WLAN Nodes vol. 3462: Springer Berlin Heidelberg, 2005.

[26] T. Bagosi and Z. Baruch, "Indoor localization by WiFi," in Intelligent Computer Communication and Processing (ICCP), 2011 IEEE International Conference on, 2011, pp. 449-452.

[27] J. Hallberg, M. Nilsson, and K. Synnes, "Positioning with Bluetooth," in Telecommunications, 2003. ICT 2003. 10th International Conference on, 2003, pp. 954-958 vol.2.

[28] T. King, H. Lemelson, A. Farber, and W. Effelsberg, "BluePos: Positioning with Bluetooth," in Intelligent Signal Processing, 2009. WISP 2009. IEEE International Symposium on, 2009, pp. 55-60.

[29] D. C. Ortiz C, M. A. Jimenez V, and J. D. Cely Callejas, "Indoor localization prototype using ZigBee," in Circuits and Systems (CWCAS), 2012 IEEE 4th Colombian Workshop on, 2012, pp. 1-7.

[30] C. Kuek Ser, K. Ng Yew, M. F. Burhan, N. Balasubramaniam, and N. Md Din, "ZigBee environment for indoor localization," in Engineering Technology and Technopreneuship (ICE2T), 2014 4th International Conference on, 2014, pp. 152-155. 
[31] L. Pierucci and P. J. Roig, "UWB localization on indoor MIMO channels," in Wireless Networks, Communications and Mobile Computing, 2005 International Conference on, 2005, pp. 890-894 vol.2.

[32] M. Kuhn, Z. Cemin, B. Merkl, Y. Depeng, W. Yazhou, M. Mahfouz, et al., "High accuracy UWB localization in dense indoor environments," in Ultra-Wideband, 2008. ICUWB 2008. IEEE International Conference on, 2008, pp. 129-132.

[33] Q. Yuan and I. M. Chen, "3-D Localization of Human Based on an Inertial Capture System," IEEE Transactions on Robotics, vol. 29, pp. 806-812, 2013.

[34] J. Blankenbach, A. Norrdine, and H. Hellmers, "A robust and precise 3D indoor positioning system for harsh environments," in Indoor Positioning and Indoor Navigation (IPIN), 2012 International Conference on, 2012, pp. 1-8.

[35] X. Jiang, C. J. M. Liang, K. Chen, B. Zhang, J. Hsu, J. Liu, et al., "Design and evaluation of a wireless magnetic-based proximity detection platform for indoor applications," in Information Processing in Sensor Networks (IPSN), 2012 ACM/IEEE 11th International Conference on, 2012, pp. 221-231.

[36] H. Dai and D. Su, "Indoor location system using RFID and ultrasonic sensors," in Antennas, Propagation and EM Theory, 2008. ISAPE 2008. 8th International Symposium on, 2008, pp. 11791181.

[37] J. Choliz, M. Eguizabal, A. Hernandez-Solana, and A. Valdovinos, "Comparison of Algorithms for UWB Indoor Location and Tracking Systems," in Vehicular Technology Conference (VTC Spring), 2011 IEEE 73rd, 2011, pp. 1-5.

[38] Z. Feng-Juan, W. Zong-heng, H. Bin-Jie, C. Jian-Guang, and G. Zi-min, "Analysis of Indoor Positioning Approaches Based on Active RFID," in Wireless Communications, Networking and Mobile Computing, 2009. WiCom '09. 5th International Conference on, 2009, pp. 1-4.

[39] F. Adib, H. Mao, Z. Kabelac, D. Katabi, and R. C. Miller, "Smart Homes that Monitor Breathing and Heart Rate," presented at the Proceedings of the 33rd Annual ACM Conference on Human Factors in Computing Systems, Seoul, Republic of Korea, 2015.

[40] X. Liu, J. Cao, S. Tang, J. Wen, and P. Guo, "Contactless Respiration Monitoring Via Off-the-Shelf WiFi Devices," IEEE Transactions on Mobile Computing, vol. 15, pp. 2466-2479, 2016.

[41] J. Liu, Y. Wang, Y. Chen, J. Yang, X. Chen, and J. Cheng, "Tracking Vital Signs During Sleep Leveraging Off-the-shelf WiFi," presented at the Proceedings of the 16th ACM International Symposium on Mobile Ad Hoc Networking and Computing, Hangzhou, China, 2015.

[42] F. Manzoor and K. Menzel, "Indoor localisation for complex building designs using passive RFID technology," in General Assembly and Scientific Symposium, 2011 XXXth URSI, 2011, pp. 1-4.

[43] F. Manzoor, D. Linton, and M. Loughlin, "Occupancy Monitoring Using Passive RFID Technology for Efficient Building Lighting Control," in 2012 Fourth International EURASIP Workshop on RFID Technology, 2012, pp. 83-88.

[44] O. Kaltiokallio, M. Bocca, and N. Patwari, "A Fade Level-Based Spatial Model for Radio Tomographic Imaging," IEEE Transactions on Mobile Computing, vol. 13, pp. 1159-1172, 2014.

[45] H. Wang, D. Zhang, Y. Wang, J. Ma, Y. Wang, and S. Li, "RT-Fall: A Real-Time and Contactless Fall Detection System with Commodity WiFi Devices," IEEE Transactions on Mobile Computing, vol. 16, pp. 511-526, 2017.

[46] G. A. Oguntala, H. A. Obeidat, M. A. Khambashi, F. Elmegri, R. A. A. Alhameed, T. Yuxiang, et al., "'Design Framework for Unobtrusive Patient Location Recognition using Passive RFID and Particle Filtering"," presented at the 7th IEEE International Conference on Internet Technologies \& Applications, Wrexham, North Wales, UK, 2017.

[47] G. A. Oguntala, R. A. Abd-Alhameed, S. M. R. Jones, and J. M. Noras, "Unobtrusive mobile approach to patient location and orientation recognition for elderly care homes," in 2017 13th International Wireless Communications and Mobile Computing Conference (IWCMC), 2017, pp. 1517-1521.

[48] Y. Zeng, P. H. Pathak, and P. Mohapatra, "Analyzing Shopper's Behavior through WiFi Signals," presented at the Proceedings of the 2nd workshop on Workshop on Physical Analytics, Florence, Italy, 2015.

[49] M. G. Puyol, D. Bobkov, P. Robertson, and T. Jost, "Pedestrian Simultaneous Localization and Mapping in Multistory Buildings Using Inertial Sensors," IEEE Transactions on Intelligent Transportation Systems, vol. 15, pp. 1714-1727, 2014.

[50] G. Tan, M. Lu, F. Jiang, K. Chen, X. Huang, and J. Wu, "Bumping: A Bump-Aided Inertial Navigation Method for Indoor Vehicles Using Smartphones," IEEE Transactions on Parallel and Distributed Systems, vol. 25, pp. 1670-1680, 2014.

[51] Xandem. (2017). Xandem Home creates a movement-detecting sensing web around the house. Available: www.xandem.com 
[52] A. T. Mariakakis, S. Sen, J. Lee, and K.-H. Kim, "SAIL: single access point-based indoor localization," presented at the Proceedings of the 12th annual international conference on Mobile systems, applications, and services, Bretton Woods, New Hampshire, USA, 2014.

[53] L. Atzori, A. Iera, and G. Morabito, "The Internet of Things: A survey," Comput. Netw., vol. 54, pp. 2787-2805, 2010.

[54] E. Bekir, Introduction To Modern Navigation Systems. Singapore: World Scientific Publishing Co. Pte. Ltd., 2007.

[55] O. J. Woodman, "An introduction to inertial navigation," University of Cambridge, United Kingdom, Technical UCAM-CL-TR-696, August 20072007.

[56] F. Höflinger, J. Müller, R. Zhang, L. M. Reindl, and W. Burgard, "A Wireless Micro Inertial Measurement Unit (IMU)," IEEE Transactions on Instrumentation and Measurement, vol. 62, pp. 2583-2595, 2013.

[57] H. Chun-Chieh and H. Polly, "Two Practical Considerations of Beacon Deployment for UltrasoundBased Indoor Localization Systems," in Sensor Networks, Ubiquitous and Trustworthy Computing, 2008. SUTC '08. IEEE International Conference on, 2008, pp. 306-311.

[58] T. Javed, "Enabling Indoor Location-based Services Using Ultrasound," Master of Science, School of Computing, Queen's University, Kingston, Ontario, Canada, 2013.

[59] Y.-T. Wang, J. Li, R. Zheng, and D. Zhao, "ARABIS: an Asynchronous Acoustic Indoor Positioning System for Mobile Devices," Cornell University Library, 2017.

[60] W.-C. W. Haitao Bao, "A Novel Map-Based Dead-Reckoning Algorithm for Indoor Localization," Journal of Sensor and Actuator Networks, vol. 3, pp. 44-63, 3 January 20142014.

[61] J. C. S. C. Medina, A. De la Torre, "Ultrasound Indoor Positioning System Based on a Low-Power Wireless Sensor Network Providing Sub-Centimeter Accuracy," Journal of Sensors, vol. 13, p. 25, March 132013.

[62] K. Wroble, "Performance Analysis of Magnetic Indoor Local Positioning System," M.Sc., Electrical and Computer Engineering, Western Michigan University, Michigan, USA, 2015.

[63] H.-S. Kim, W. Seo, and K.-R. Baek, "Indoor Positioning System Using Magnetic Field Map Navigation and an Encoder System," Sensors (Basel, Switzerland), vol. 17, p. 651, 2017.

[64] C. P. a. M. M. Eric Brassart, "Localization using infrared beacons," Cambridge Journal: Robotica, vol. 18 pp. 153-161, 08 September 20002000.

[65] D. Hauschildt and N. Kirchhof, "Improving indoor position estimation by combining active TDOA ultrasound and passive thermal infrared localization," in Positioning Navigation and Communication (WPNC), 2011 8th Workshop on, 2011, pp. 94-99.

[66] S. L. a. J.-B. S. Jungyun Bae, "Use of coded infrared light for mobile robot localization " Journal of Mechanical Science and Technology vol. 22, p. 1279 1286, March 31, 20082008.

[67] D. Hauschildt and N. Kirchhof, "Advances in thermal infrared localization: Challenges and solutions," in Indoor Positioning and Indoor Navigation (IPIN), 2010 International Conference on, 2010, pp. 1-8.

[68] J. Kemper and D. Hauschildt, "Passive infrared localization with a Probability Hypothesis Density filter," in Positioning Navigation and Communication (WPNC), 2010 7th Workshop on, 2010, pp. 6876.

[69] S. I. Megumu Tsuchikawa, Sadanori Ito, Atsushi Nakahara, Yasuyuki Sumi, Kenji Mase, Kiyoshi Kogure, Norihiro Hagita, "Experience-Sharing System Using Ubiquitous Sensing Environments," in Ubiquitous Computing Systems, H. N. Hitomi Murakami, Hideyuki Tokuda, Michiaki Yasumura, Ed., ed Tokyo, Japan: Springer, 2005, pp. 90-103.

[70] T. G. Xie Bo, Liu Yunhuai, Lu Mingming, Chen Kongyang, He Tian, "LIPS: A Light Intensity Based Positioning System For Indoor Environments," International Journal of Information Processing, vol. 7 , pp. 15-29, 03/2014 2014.

[71] F. K. M. Ehmer Khan, "An Empirical Study of Different Wireless Network Communication and Ways to Optimize its Performance and Seed," International Journal of Computer Applications, vol. 46, pp. 44-50, 2012.

[72] A. Makki, A. Siddig, M. Saad, J. R. Cavallaro, and C. J. Bleakley, "Indoor Localization Using 802.11 Time Differences of Arrival," Instrumentation and Measurement, IEEE Transactions on, vol. PP, pp. 1-10, 2016.

[73] Y. Chouchang and S. Huai-rong, "WiFi-based indoor positioning," Communications Magazine, IEEE, vol. 53, pp. 150-157, 2015.

[74] R. F. a. R. Harle, "An Analysis of the Accuracy of Bluetooth Low Energy for Indoor Positioning Applications," in 27th International Technical Meeting of The Satellite Division of the Institute of Navigation (ION GNSS+ 2014), Tampa Convention Center, Tampa, Florida, USA, 2014, pp. 201 - 210. 
[75] C. Chen, Y. Chen, H. Lai, Y. Han, and K. J. R. Liu, "High accuracy indoor localization: A WiFi-based approach," in 2016 IEEE International Conference on Acoustics, Speech and Signal Processing (ICASSP), 2016, pp. 6245-6249.

[76] A. S. Ahmed Makki, Mohamed Saad, Chris Bleakley, "Survey of WiFi positioning using time-based techniques," Computer Networks: Elsevier, vol. 88, pp. 218-233, 9 September 20152015.

[77] C. Yongguang and H. Kobayashi, "Signal strength based indoor geolocation," in Communications, 2002. ICC 2002. IEEE International Conference on, 2002, pp. 436-439.

[78] Y. Chapre, A. Ignjatovic, A. Seneviratne, and S. Jha, "CSI-MIMO: Indoor Wi-Fi fingerprinting system," in 39th Annual IEEE Conference on Local Computer Networks, 2014, pp. 202-209.

[79] C. Xu, Z. Jia, P. Chen, and B. Wang, "CSI-based autoencoder classification for Wi-Fi indoor localization," in 2016 Chinese Control and Decision Conference (CCDC), 2016, pp. 6523-6528.

[80] C. Chen, Y. Chen, H. Q. Lai, Y. Han, and K. J. R. Liu, "High accuracy indoor localization: A WiFibased approach," in 2016 IEEE International Conference on Acoustics, Speech and Signal Processing (ICASSP), 2016, pp. 6245-6249.

[81] S. S. I. Kenneth C. Cheung, Kent Larson, "An Inexpensive Bluetooth-Based Indoor Positioning Hack," p. 2, 2006.

[82] D. Scheerens, "Practical Indoor Localization using Bluetooth," M.Sc., Information Systems Engineering, University of Twente, 2012.

[83] C. Kuor-Hsin, "Bluetooth: a viable solution for IoT? [Industry Perspectives]," Wireless Communications, IEEE, vol. 21, pp. 6-7, 2014.

[84] N. Mair and Q. H. Mahmoud, "A collaborative Bluetooth-based approach to localization of mobile devices," in Collaborative Computing: Networking, Applications and Worksharing (CollaborateCom), 2012 8th International Conference on, 2012, pp. 363-371.

[85] J.-H. Huh and K. Seo, "An Indoor Location-Based Control System Using Bluetooth Beacons for IoT Systems," Sensors, MDPI (Basel, Switzerland), vol. 17, p. 2917, 2017.

[86] S. S. Chawathe, "Beacon Placement for Indoor Localization using Bluetooth," in Intelligent Transportation Systems, 2008. ITSC 2008. 11th International IEEE Conference on, 2008, pp. 980-985.

[87] A. Bekkelien, "Bluetooth Indoor Positioning," M.Sc., Computer Science, University of Geneva, Switzerland, 2012.

[88] P. Baronti, P. Pillai, V. W. C. Chook, S. Chessa, A. Gotta, and Y. F. Hu, "Wireless sensor networks: A survey on the state of the art and the 802.15.4 and ZigBee standards," Computer Communications, vol. 30, pp. 1655-1695, 5/26/ 2007.

[89] J. D. Lee, K. Y. Nam, S. H. Jeong, S. B. Choi, H. S. Ryoo, and D. K. Kim, "Development of Zigbee based Street Light Control System," in Power Systems Conference and Exposition, 2006. PSCE '06. 2006 IEEE PES, 2006, pp. 2236-2240.

[90] K. Jong-Won, P. Yong-Man, K. Sang-Jun, and K. Jo Chun, "Design of Air Pollution Monitoring System Using ZigBee Networks for Ubiquitous-City," in Convergence Information Technology, 2007. International Conference on, 2007, pp. 1024-1031.

[91] C. P. Sangeetha and C. D. Suriyakala, "Performance analysis of IEEE 802.15.4/ZigBee sensor networks using ADAPT algorithm," in Control, Instrumentation, Communication and Computational Technologies (ICCICCT), 2014 International Conference on, 2014, pp. 676-683.

[92] A. K. Akshay Kanwar, "ZigBee: The New Bluetooth Technology," International Journal Of Engineering And Computer Science, vol. 1, p. 9, 2012.

[93] M. Aykaç, E. Erçelebi, and N. Baha Aldin, "ZigBee-based indoor localization system with the personal dynamic positioning method and modified particle filter estimation," Analog Integrated Circuits and Signal Processing, vol. 92, pp. 263-279, 2017/08/01 2017.

[94] C.-N. Huang and C.-T. Chan, "ZigBee-based indoor location system by k-nearest neighbor algorithm with weighted RSSI," Procedia Computer Science, vol. 5, pp. 58-65, // 2011.

[95] S. Tadakamadla, "Indoor Local Positioning System For ZigBee, Based On RSSI," M.Sc., Department of Information Technology and Media, Mid Sweden University, Sweden, 2006.

[96] J. Larranaga, L. Muguira, J. M. Lopez-Garde, and J. I. Vazquez, "An environment adaptive ZigBeebased indoor positioning algorithm," in Indoor Positioning and Indoor Navigation (IPIN), 2010 International Conference on, 2010, pp. 1-8.

[97] B. Amutha and K. Nanmaran, "Development of a ZigBee based virtual eye for visually impaired persons," in Indoor Positioning and Indoor Navigation (IPIN), 2014 International Conference on, 2014, pp. 564-574.

[98] R. Divyabharathi, C. A. Hakeem, and A. M. Mian, "Design and simulation of Zigbee Transmitter using Verilog," in Information Communication and Embedded Systems (ICICES), 2013 International Conference on, 2013, pp. 882-888. 
[99] N. Jianwei, W. Bowei, S. Lei, T. Q. Duong, and C. Yuanfang, "ZIL: An Energy-Efficient Indoor Localization System Using ZigBee Radio to Detect WiFi Fingerprints," Selected Areas in Communications, IEEE Journal on, vol. 33, pp. 1431-1442, 2015.

[100] Y. Fang and Y. Shuang-Hua, "Design of interference aware ZigBee building monitoring network," in Automation and Computing (ICAC), 2011 17th International Conference on, 2011, pp. 57-62.

[101] C. Gomez and J. Paradells, "Wireless home automation networks: A survey of architectures and technologies," Communications Magazine, IEEE, vol. 48, pp. 92-101, 2010.

[102] D. I. J. Sachs, Handbook of Ultra-Wideband Short-Range Sensing. Germany: Wiley-VCH Verlag, 2012.

[103] J. A. K. Leung Tsang, kung-hau Ding, Scattering of Electromagnetic Waves, Theories and Applications. New York, USA: John Wiley \& Sons Inc., 2000.

[104] E. G. Jeff Foerster, Srinivasa Somayazulu, David Leeper, "Ultra-Wideband Technology for Short-or Medium-Range Wireless Communication," Intel Technology Journal, p. 11, 2001.

[105] Y. Pinhasi, A. Yahalom, O. Harpaz, and G. Vilner, "Study of ultrawide-band transmission in the extremely high frequency (EHF) band," Antennas and Propagation, IEEE Transactions on, vol. 52, pp. 2833-2842, 2004.

[106] I. Oppermann, M. Hämäläinen, and J. Iinatti, UWB Theory and Applications. Sussex, England: John Wiley \& Sons, Ltd, 2005.

[107] M. Ridolfi, S. Vandermeeren, J. Defraye, H. Steendam, J. Gerlo, D. De Clercq, et al., "Experimental Evaluation of UWB Indoor Positioning for Sport Postures," Sensors, vol. 18, p. 168, 2018.

[108] S. J. Ingram, D. Harmer, and M. Quinlan, "UltraWideBand indoor positioning systems and their use in emergencies," in Position Location and Navigation Symposium, 2004. PLANS 2004, 2004, pp. 706715 .

[109] Y. Rahayu, T. A. Rahman, R. Ngah, and P. S. Hall, "Ultra wideband technology and its applications," in Wireless and Optical Communications Networks, 2008. WOCN '08. 5th IFIP International Conference on, 2008, pp. 1-5.

[110] M. H. Ian Oppermann, Jari Linatti, UWB Theory and Applications. West Sussex, England: John Wiley \& Sons, 2004.

[111] S. Ullah, M. Ali, A. Hussain, and K. S. Kwak, "Applications of UWB technology," arXiv preprint arXiv:0911.1681, 2009.

[112] R. Chase, "UWB: Fostering Innovation Through a Balanced Regulatory Framework," Federal Communication Commission, USA11 April, 20062006.

[113] L. Jin-Shyan, S. Yu-Wei, and S. Chung-Chou, "A Comparative Study of Wireless Protocols: Bluetooth, UWB, ZigBee, and Wi-Fi," in Industrial Electronics Society, 2007. IECON 2007. 33rd Annual Conference of the IEEE, 2007, pp. 46-51.

[114] B. Radunovic and J. Y. Le Boudec, "Optimal power control, scheduling, and routing in UWB networks," Selected Areas in Communications, IEEE Journal on, vol. 22, pp. 1252-1270, 2004.

[115] B. S. Cook, R. Vyas, K. Sangkil, T. Trang, L. Taoran, A. Traille, et al., "RFID-Based Sensors for ZeroPower Autonomous Wireless Sensor Networks," Sensors Journal, IEEE, vol. 14, pp. 2419-2431, 2014.

[116] M. Bouet and A. L. dos Santos, "RFID tags: Positioning principles and localization techniques," in Wireless Days, 2008. WD '08. 1st IFIP, 2008, pp. 1-5.

[117] L. Weifeng, W. Jun, and W. Dong, "A novel indoor positioning method based on key reference RFID tags," in Information, Computing and Telecommunication, 2009. YC-ICT '09. IEEE Youth Conference on, 2009, pp. 42-45.

[118] G. Oguntala, H. Obeidat, M. A. Khambashi, F. Elmegri, R. A. Abd-Alhameed, T. Yuxiang, et al., "Design framework for unobtrusive patient location recognition using passive RFID and particle filtering," in 2017 Internet Technologies and Applications (ITA), 2017, pp. 212-217.

[119] S. W. Yuntian Brian Bai, Hongren Wu, Kefei Zhang, "Overview of RFID-Based Indoor Positioning Technology," presented at the Melbourne: Geospatial Sciences, RMIT 2012, Melbourne, Australia, 2012.

[120] C. Xu, Y. Alfadhl, and C. Kok Keong, "An indoor item finder with active RFID tags," in Communication Technology and Application (ICCTA 2011), IET International Conference on, 2011, pp. 675-683.

[121] M. A. Khan and V. K. Antiwal, "Location Estimation Technique using Extended 3-D LANDMARC Algorithm for Passive RFID Tag," in Advance Computing Conference, 2009. IACC 2009. IEEE International, 2009, pp. 249-253.

[122] G. Oguntala;, R. Abd-Alhameed;, E. Nnabuike;, and J. Noras;, "SmartWall: Experimental Validation of RFID-enabled Human Activity Recognition using Multivariate Gaussian for Unobtrusive Health Monitoring," Unpublished, 2018. 
[123] M. S. M. Kaur, N. Mohan and P. S. Sandhu, "RFID Technology Principles, Advantages, Limitations \& Its Applications," International Journal of Computer and Electrical Engineering, vol. 3, p. 7, February, 20112011.

[124] Stephen Reutebuch, Hans-Erik Andersen, and R. McGaughey, "Light detection and ranging (LIDAR): an emerging tool for multiple resource inventory.," Journal of Forestry, pp. 286-292, 2005.

[125] I. Bogoslavskyi and C. Stachniss, "Efficient Online Segmentation for Sparse 3D Laser Scans," PFG Journal of Photogrammetry, Remote Sensing and Geoinformation Science, vol. 85, pp. 41-52, February 012017.

[126] Y. Fan, L. Zheng, and Y. Liu, "3D Environment Measurement and Reconstruction Based on LiDAR," in 2018 IEEE International Instrumentation and Measurement Technology Conference (I2MTC), 2018, pp. 1-4.

[127] M. J. Gallant and J. A. Marshall, "Two-Dimensional Axis Mapping Using LiDAR," IEEE Transactions on Robotics, vol. 32, pp. 150-160, 2016.

[128] J. Li, X. He, and J. Li, "2D LiDAR and camera fusion in 3D modeling of indoor environment," in 2015 National Aerospace and Electronics Conference (NAECON), 2015, pp. 379-383.

[129] T. Shamseldin, A. Manerikar, M. Elbahnasawy, and A. Habib, "SLAM-based Pseudo-GNSS/INS localization system for indoor LiDAR mobile mapping systems," in 2018 IEEE/ION Position, Location and Navigation Symposium (PLANS), 2018, pp. 197-208.

[130] A. V. Jochen Schiller, Location Based Services. CA, United State of America: Morgan Kaufman Publishing, Elsevier, 2004.

[131] N. Alsindi, L. Xinrong, and K. Pahlavan, "Performance of TOA estimation algorithms in different indoor multipath conditions," in Wireless Communications and Networking Conference, 2004. WCNC. 2004 IEEE, 2004, pp. 495-500 Vol.1.

[132] H. Jie, K. Pahlavan, L. Shen, and W. Qin, "A Testbed for Evaluation of the Effects of Multipath on Performance of TOA-Based Indoor Geolocation," Instrumentation and Measurement, IEEE Transactions on, vol. 62, pp. 2237-2247, 2013.

[133] Z. Jinkang and Z. Jinkang, "A new model and its performance for TDOA estimation," in Vehicular Technology Conference, 2001. VTC 2001 Fall. IEEE VTS 54th, 2001, pp. 2750-2753 vol.4.

[134] H. Di, Y. Liu, and J. Yang, "TDOA accurate estimation algorithm based on phase calibration technique," in Computer Science and Network Technology (ICCSNT), 2013 3rd International Conference on, 2013, pp. 1083-1087.

[135] Z. Yuqiang and Z. Junhui, "Indoor localization using time difference of arrival and time-hopping impulse radio," in Communications and Information Technology, 2005. ISCIT 2005. IEEE International Symposium on, 2005, pp. 964-967.

[136] C. J. Lam and A. C. Singer, "Bayesian Beamforming for DOA Uncertainty: Theory and Implementation," Signal Processing, IEEE Transactions on, vol. 54, pp. 4435-4445, 2006.

[137] B. N. Hood and P. Barooah, "Estimating DoA From Radio-Frequency RSSI Measurements Using an Actuated Reflector," Sensors Journal, IEEE, vol. 11, pp. 413-417, 2011.

[138] W. Xinning, N. Palleit, and T. Weber, "AOD/AOA/TOA-based 3D positioning in NLOS multipath environments," in Personal Indoor and Mobile Radio Communications (PIMRC), 2011 IEEE 22nd International Symposium on, 2011, pp. 1289-1293.

[139] B. Mukhopadhyay, S. Sarangi, and S. Kar, "Novel RSSI evaluation models for accurate indoor localization with sensor networks," in Communications (NCC), 2014 Twentieth National Conference on, 2014, pp. 1-6.

[140] C. Yu-Yi and L. Yi-Yuan, "A new received signal strength based location estimation scheme for wireless sensor network," Consumer Electronics, IEEE Transactions on, vol. 55, pp. 1295-1299, 2009.

[141] S. D. a. P. H. Bram Dil, "Range-Based Localization in Mobile Sensor Networks," Wireless Sensor Netowrks, vol. 3868, pp. 164-179, 2006.

[142] D. Macii, F. Trenti, and P. Pivato, "A robust wireless proximity detection technique based on RSS and ToF measurements," in Measurements and Networking Proceedings (M\&N), 2011 IEEE International Workshop on, 2011, pp. 31-36.

[143] J. Xiaofan, C. J. M. Liang, C. Kaifei, Z. Ben, J. Hsu, L. Jie, et al., "Design and evaluation of a wireless magnetic-based proximity detection platform for indoor applications," in Information Processing in Sensor Networks (IPSN), 2012 ACM/IEEE 11th International Conference on, 2012, pp. 221-231.

[144] G. Linqing, T. Val, and A. Wei, "Improving Localization Accuracy Using Selective 3-Anchor DV-Hop Algorithm," in Vehicular Technology Conference (VTC Fall), 2011 IEEE, 2011, pp. 1-5.

[145] F. Chen, W. S. A. Au, S. Valaee, and T. Zhenhui, "Received-Signal-Strength-Based Indoor Positioning Using Compressive Sensing," Mobile Computing, IEEE Transactions on, vol. 11, pp. 1983-1993, 2012. 
[146] F. Shih-Hau, L. Tsung-Nan, and L. Kun-Chou, "A Novel Algorithm for Multipath Fingerprinting in Indoor WLAN Environments," Wireless Communications, IEEE Transactions on, vol. 7, pp. 35793588, 2008.

[147] H. Laitinen, S. Juurakko, T. Lahti, R. Korhonen, and J. Lahteenmaki, "Experimental Evaluation of Location Methods Based on Signal-Strength Measurements," Vehicular Technology, IEEE Transactions on, vol. 56, pp. 287-296, 2007.

[148] S. S. Leelavathy S. R, "Providing Localization using Triangulation Method in Wireless Sensor Networks," International Journal of Innovative Technology and Exploring Engineering, vol. 4, p. 4, November 20142014.

[149] M. Vossiek, L. Wiebking, P. Gulden, J. Weighardt, and C. Hoffmann, "Wireless local positioning concepts, solutions, applications," in Radio and Wireless Conference, 2003. RAWCON '03. Proceedings, 2003, pp. 219-224.

[150] F. Seco, A. R. Jimenez, C. Prieto, J. Roa, and K. Koutsou, "A survey of mathematical methods for indoor localization," in Intelligent Signal Processing, 2009. WISP 2009. IEEE International Symposium on, 2009, pp. 9-14.

[151] M. Malajner, D. Gleich, and P. Planinsic, "Angle of Arrival Measurement Using Multiple Static Monopole Antennas," Sensors Journal, IEEE, vol. 15, pp. 3328-3337, 2015.

[152] Q. H. Spencer, B. D. Jeffs, M. A. Jensen, and A. L. Swindlehurst, "Modeling the statistical time and angle of arrival characteristics of an indoor multipath channel," Selected Areas in Communications, IEEE Journal on, vol. 18, pp. 347-360, 2000.

[153] S. He and S. H. G. Chan, "INTRI: Contour-Based Trilateration for Indoor Fingerprint-Based Localization," IEEE Transactions on Mobile Computing, vol. 16, pp. 1676-1690, 2017.

[154] D. Fagan and R. Meier, "Intelligent time of arrival estimation," in Integrated and Sustainable Transportation System (FISTS), 2011 IEEE Forum on, 2011, pp. 60-66.

[155] H. Wymeersch, J. Lien, and M. Z. Win, "Cooperative Localization in Wireless Networks," Proceedings of the IEEE, vol. 97, pp. 427-450, 2009.

[156] M. 1. Syed A. Ahson, Location-Based Services Handbook: Applications, Technologies and Security. FL, USA: CRC Press, 2011.

[157] S. Hing Cheung, C. Yiu Tong, and F. K. W. Chan, "Closed-Form Formulae for Time-Difference-ofArrival Estimation," Signal Processing, IEEE Transactions on, vol. 56, pp. 2614-2620, 2008.

[158] M. F. P. d. Oliveira, "Magnetic Reference for Accurate Indoor Tracking," M. Sc. Masters, Electrical and Computers Engineering, FACULDADE DE ENGENHARIA DA UNIVERSIDADE DO PORTO, Porto, Portugal, 2014.

[159] C. Gentner and T. Jost, "Indoor positioning using time difference of arrival between multipath components," in Indoor Positioning and Indoor Navigation (IPIN), 2013 International Conference on, 2013, pp. 1-10.

[160] Y. Takabayashi, T. Matsuzaki, H. Kameda, and M. Ito, "Target tracking using TDOA/FDOA measurements in the distributed sensor network," in SICE Annual Conference, 2008, 2008, pp. 34413446.

[161] Y. Takabayashi, T. Matsuzaki, H. Kameda, and M. Ito, "Asynchronous track algorithm using TDOA/FDOA measurements in the distributed sensor network," in ICCAS-SICE, 2009, 2009, pp. 3032-3037.

[162] Z. Li, N. Ge, Z. Huang, and X. Chen, "A method to eliminate TDOA ambiguity based on FDOA and FDOA-rate," in Wireless Communications \& Signal Processing (WCSP), 2015 International Conference on, 2015, pp. 1-5.

[163] C. R. Comsa, L. Jianghong, A. Haimovich, and S. Schwartz, "Wireless Localization using Time Difference of Arrival in Narrow-Band Multipath Systems," in Signals, Circuits and Systems, 2007. ISSCS 2007. International Symposium on, 2007, pp. 1-4.

[164] J. Vesely, L. Drazan, and P. Hubacek, "Analytical solution of the Time Difference Of Arrival method with known target altitude," in Radar Symposium (IRS), 2014 15th International, 2014, pp. 1-4.

[165] A. Ramirez, "Time-of-flight in Wireless Networks as Information Source for Positioning," PhD, TECHNISCHE UNIVERSITÄT MÜNCHEN, Munich, Germany, 2011.

[166] A. H. Sayed, A. Tarighat, and N. Khajehnouri, "Network-based wireless location: challenges faced in developing techniques for accurate wireless location information," Signal Processing Magazine, IEEE, vol. 22 , pp. 24-40, 2005.

[167] A. Hakam, R. Shubair, E. Salahat, and A. Saadi, "Robust DOA Estimation Using a 2D Novel Smart Antenna Array," in 2014 6th International Conference on New Technologies, Mobility and Security (NTMS), 2014, pp. 1-4. 
[168] Y. Hori, Y. Doi, H. Moriya, K. Ichige, H. Arai, H. Matsuno, et al., "2D-DOA estimation under LOS environment by using pyramid shaped array antenna," in Electromagnetics (iWEM), 2013 IEEE International Workshop on, 2013, pp. 78-79.

[169] M. Pralon, D. Schulz, R. S. Thom, and x00E, "Optimization of antenna arrays for 2D DoA estimation using EADF for Cram\&\#x00E9;-Rao Lower Bounds computation," in Antennas and Propagation in Wireless Communications (APWC), 2013 IEEE-APS Topical Conference on, 2013, pp. 1429-1432.

[170] S. Wielandt, A. Van Nieuwenhuyse, J. P. Goemaere, B. Nauwelaers, and L. De Strycker, "Evaluation of angle of arrival estimation for localization in multiple indoor environments," in Ubiquitous Positioning Indoor Navigation and Location Based Service (UPINLBS), 2014, 2014, pp. 36-43.

[171] S. J. Nawaz, N. M. Khan, M. N. Patwary, and M. Moniri, "Effect of Directional Antenna on the Doppler Spectrum in 3-D Mobile Radio Propagation Environment," Vehicular Technology, IEEE Transactions on, vol. 60, pp. 2895-2903, 2011.

[172] P. Petrus, J. H. Reed, and T. S. Rappaport, "Effects of directional antennas at the base station on the Doppler spectrum," Communications Letters, IEEE, vol. 1, pp. 40-42, 1997.

[173] Y. Liu, L. Song, X. Ni, J. Qi, and Z. Liu, "Measurement of angle-of-arrival fluctuations over a real atmospheric turbulent path," in Optoelectronics and Microelectronics (ICOM), 2015 International Conference on, 2015, pp. 160-164.

[174] I. Jami and R. F. Ormondroyd, "Improved method for estimating angle of arrival in multipath conditions using the 'MUSIC' algorithm," in Antennas and Propagation for Wireless Communications, 2000 IEEE-APS Conference on, 2000, pp. 99-102.

[175] M. Werner, Indoor Location-Based Services: Prerequisites and Foundations. New York: Springers, 2014.

[176] T. Teixeira, D. Jung, and A. Savvides, "Tasking networked CCTV cameras and mobile phones to identify and localize multiple people," presented at the Proceedings of the 12th ACM international conference on Ubiquitous computing, Copenhagen, Denmark, 2010.

[177] B. Brumitt, B. Meyers, J. Krumm, A. Kern, and S. Shafer, "EasyLiving: Technologies for Intelligent Environments," in Handheld and Ubiquitous Computing, P. Thomas and H.-W. Gellersen, Eds., ed Germany: Springer Berlin Heidelberg, 2000, pp. 12-29.

[178] R. Abielmona and V. Groza, "Indoor Sensor Networks: Localization Schemes," in Electrical and Computer Engineering, 2007. CCECE 2007. Canadian Conference on, 2007, pp. 1078-1081.

[179] N. M. S. D.H. Stojanović, "Indoor Localization and Tracking - Methods Technologies and Research Challenges," Automatic Control and Robotics, vol. 13, pp. 57-72, 2014.

[180] I. Bisio, A. Sciarrone, and S. Zappatore, "Asset tracking architecture with Bluetooth Low Energy tags and ad hoc smartphone applications," in Networks and Communications (EuCNC), 2015 European Conference on, 2015, pp. 460-464.

[181] G. Han, G. J. Klinker, D. Ostler, and A. Schneider, "Testing a proximity-based location tracking system with Bluetooth Low Energy tags for future use in the OR," in 2015 17th International Conference on E-health Networking, Application \& Services (HealthCom), 2015, pp. 17-21.

[182] W. Liu, B. Q. Ng, T. Lim, L. Bin, B. H. Soong, A. Nasir, et al., "A novel RFID and capacitive sensing based smart bookshelf," in 2012 18th IEEE International Conference on Networks (ICON), 2012, pp. 92-97.

[183] Y. Nishida, "Proximity Motion Detection Using 802.11 for Mobile Devices," in Portable Information Devices, 2007. PORTABLE07. IEEE International Conference on, 2007, pp. 1-5.

[184] M. Gupta and N. Sharma, "Localization of Nodes: A New Challenge for Wireless Sensor Networks," International Journal of Computer Applications, vol. 72, 2013.

[185] Y. Chapre, P. Mohapatra, S. Jha, and A. Seneviratne, "Received signal strength indicator and its analysis in a typical WLAN system (short paper)," in Local Computer Networks (LCN), 2013 IEEE 38th Conference on, 2013, pp. 304-307.

[186] K. Chetcuti, C. J. Debono, and S. Bruillot, "The effect of human shadowing on RF signal strengths of IEEE802.11a systems on board business jets," in Aerospace Conference, 2010 IEEE, 2010, pp. 1-9.

[187] S. A. Elsagheer Mohamed, "Why The Accuracy Of The Received Signal Strengths As A Positioning Technique Was Not Accurate?," International Journal of Wireless \& Mobile Networks, vol. 3, pp. 6982, 2011.

[188] K. Wu, J. Xiao, Y. Yi, D. Chen, X. Luo, and L. M. Ni, "CSI-Based Indoor Localization," IEEE Transactions on Parallel and Distributed Systems, vol. 24, pp. 1300-1309, 2013.

[189] X. Wang, L. Gao, S. Mao, and S. Pandey, "CSI-Based Fingerprinting for Indoor Localization: A Deep Learning Approach," IEEE Transactions on Vehicular Technology, vol. 66, pp. 763-776, 2017.

[190] D. Halperin, W. Hu, A. Sheth, and D. Wetherall, "Predictable 802.11 packet delivery from wireless channel measurements," SIGCOMM Comput. Commun. Rev., vol. 41, pp. 159-170, 2010. 
[191] J. Li, Y. Li, and X. Ji, "A novel method of Wi-Fi indoor localization based on channel state information," in 2016 8th International Conference on Wireless Communications \& Signal Processing (WCSP), 2016, pp. 1-5.

[192] J. Xiao, K. Wu, Y. Yi, L. Wang, and L. M. Ni, "Pilot: Passive Device-Free Indoor Localization Using Channel State Information," in 2013 IEEE 33rd International Conference on Distributed Computing Systems, 2013, pp. 236-245.

[193] X. Wang, Y. Liu, Z. Shi, X. Lu, and L. Sun, "A Privacy-Preserving Fuzzy Localization Scheme with CSI Fingerprint," in 2015 IEEE Global Communications Conference (GLOBECOM), 2015, pp. 1-6.

[194] W.-s. M. Bong-Su Cho, Woo-Jin Seo and Kwang-Ryul Baek, "A dead reckoning localization system for mobile robots using inertial sensors and wheel revolution encoding," Journal of Mechanical Science and Technology, vol. 25, p. 2907 2917, 2011.

[195] L. Ojeda and J. Borenstein, "Personal Dead-reckoning System for GPS-denied Environments," in Safety, Security and Rescue Robotics, 2007. SSRR 2007. IEEE International Workshop on, 2007, pp. 16.

[196] Q. Guo, O. Bebek, M. C. Cavusoglu, C. H. Mastrangelo, and D. J. Young, "A personal navigation system using MEMS-based high-density ground reaction sensor array and inertial measurement unit," in Solid-State Sensors, Actuators and Microsystems (TRANSDUCERS), 2015 Transducers - 2015 18th International Conference on, 2015, pp. 1077-1080.

[197] M. Ibraheem, "Gyroscope-enhanced dead reckoning localization system for an intelligent Walker," in Information Networking and Automation (ICINA), 2010 International Conference on, 2010, pp. V1-67V1-72.

[198] A. Widyotriatmo and H. Keum-Shik, "Navigation Function-Based Control of Multiple Wheeled Vehicles," Industrial Electronics, IEEE Transactions on, vol. 58, pp. 1896-1906, 2011.

[199] J. Borenstein and F. Liqiang, "Measurement and correction of systematic odometry errors in mobile robots," Robotics and Automation, IEEE Transactions on, vol. 12, pp. 869-880, 1996.

[200] M. Golfarelli, D. Maio, and S. Rizzi, "Elastic correction of dead-reckoning errors in map building," in Intelligent Robots and Systems, 1998. Proceedings., 1998 IEEE/RSJ International Conference on, 1998, pp. 905-911 vol.2.

[201] M. Golfarelli, D. Maio, and S. Rizzi, "Correction of dead-reckoning errors in map building for mobile robots," Robotics and Automation, IEEE Transactions on, vol. 17, pp. 37-47, 2001.

[202] D. M. D. Bartosz S. JACHIMCZYK1, Wlodek J. KULESZA2, "Performance Aalysis of an RFIDbased 3D indoor Positioning System combining Scene Analysis and Neural Network Methods.pdf," Zeszyty Naukowe Wydziału Elektrotechniki i Automatyki Politechniki Gdańskiej, vol. 34, 2013.

[203] B. Jachimczyk, D. Dziak, and W. J. Kulesza, "RFID - Hybrid Scene Analysis-Neural Network system for 3D Indoor Positioning optimal system arrangement approach," in Instrumentation and Measurement Technology Conference (I2MTC) Proceedings, 2014 IEEE International, 2014, pp. 191196.

[204] C. Gentile, Alsindi, N., Raulefs, R., Teolis, C., Geolocation Techniques: Principles and Applications: Spinger, 2013.

[205] L. Wei-Chia, S. Ying-Ying, L. Chih-Ming, F. Shih-Hau, L. Wan-Jung, H. Xu-Peng, et al., "A survey of secure fingerprinting localization in wireless local area networks," in Machine Learning and Cybernetics (ICMLC), 2013 International Conference on, 2013, pp. 1413-1417.

[206] T. Chuenurajit, S. Phimmasean, and P. Cherntanomwong, "Robustness of 3D indoor localization based on fingerprint technique in wireless sensor networks," in Electrical Engineering/Electronics, Computer, Telecommunications and Information Technology (ECTI-CON), 2013 10th International Conference on, 2013, pp. 1-6.

[207] M. Hatami, M. Jafaryar, D. D. Ganji, and M. Gorji-Bandpy, "Optimization of finned-tube heat exchangers for diesel exhaust waste heat recovery using CFD and CCD techniques," International Communications in Heat and Mass Transfer, vol. 57, pp. 254-263, 2014/10/01/ 2014.

[208] J. Zhiping, Z. Jizhong, H. Jinsong, T. Shaojie, Z. Jing, and X. Wei, "Wi-Fi Fingerprint Based Indoor Localization without Indoor Space Measurement," in Mobile Ad-Hoc and Sensor Systems (MASS), 2013 IEEE 10th International Conference on, 2013, pp. 384-392.

[209] L. Xing-Yu, H. Ke, and Y. Min, "Research on improvement to WiFi fingerprint location algorithm," in Wireless Communications, Networking and Mobile Computing (WiCOM 2014), 10th International Conference on, 2014, pp. 648-652.

[210] L. Dongjae, C. Kyoungtaek, and K. Jaihie, "A robust fingerprint matching algorithm using local alignment," in Pattern Recognition, 2002. Proceedings. 16th International Conference on, 2002, pp. 803-806 vol.3. 
[211] L. Hefei, W. Shanshan, W. Liyun, and Z. Fuhao, "A real-time robust digital fingerprinting algorithm," in Signal Processing (ICSP), 2010 IEEE 10th International Conference on, 2010, pp. 1869-1872.

[212] W. Hongxue, Y. Xiaoqing, W. WangGen, and R. Swaminathan, "Robust audio fingerprint extraction algorithm based on 2-D chroma," in Audio, Language and Image Processing (ICALIP), 2012 International Conference on, 2012, pp. 763-767.

[213] S. Iftikhar, Z. Anwar, and M. Kamran, "A novel and robust fingerprinting technique for digital data based on Genetic Algorithm," in High-capacity Optical Networks and Emerging/Enabling Technologies (HONET), 2014 11th Annual, 2014, pp. 173-177.

[214] Q. Jin and X. Mei, "A robust algorithm for fingerprint singular point detection and image reference direction determination based on the analysis of curvature map," in Cybernetics and Intelligent Systems, 2008 IEEE Conference on, 2008, pp. 1051-1054.

[215] A. Sengupta and S. Mukhopadhyay, "A robust algorithm for fingerprint core-point detection," in Students' Technology Symposium (TechSym), 2011 IEEE, 2011, pp. 154-159.

[216] X. Wei, Y. Xiaoqing, and S. Jianhua, "An improved audio fingerprinting algorithm with robust and efficient," in Smart and Sustainable City 2013 (ICSSC 2013), IET International Conference on, 2013, pp. 377-380.

[217] L. Yue Nan, "Robust Content Fingerprinting Algorithm Based on Sparse Coding," Signal Processing Letters, IEEE, vol. 22, pp. 1254-1258, 2015.

[218] F. Jianjiang, S. Yuan, and Z. Jie, "Robust and Efficient Algorithms for Separating Latent Overlapped Fingerprints," Information Forensics and Security, IEEE Transactions on, vol. 7, pp. 1498-1510, 2012.

[219] H. A. Karimi, T. Conahan, and D. Roongpiboonsopit, "A Methodology for Predicting Performances of Map-Matching Algorithms," in Web and Wireless Geographical Information Systems: 6th International Symposium, W2GIS 2006, Hong Kong, China, December 4-5, 2006. Proceedings, J. D. Carswell and T. Tezuka, Eds., ed Berlin, Heidelberg: Springer Berlin Heidelberg, 2006, pp. 202-213.

[220] M. Khider, S. Kaiser, and P. Robertson, "A Novel Three Dimensional Movement Model for Pedestrian Navigation," Journal of Navigation, vol. 65, pp. 245-264, 2012.

[221] W. Elloumi, A. Latoui, R. Canals, A. Chetouani, and S. Treuillet, "Indoor Pedestrian Localization With a Smartphone: A Comparison of Inertial and Vision-Based Methods," IEEE Sensors Journal, vol. 16, pp. 5376-5388, 2016.

[222] K. E. Mokhtari, S. Reboul, J. B. Choquel, B. Amami, and M. Benjelloun, "Indoor localization by particle map matching," in 2016 4th IEEE International Colloquium on Information Science and Technology (CiSt), 2016, pp. 812-817.

[223] D. Bernstein and A. Kornhauser, "AN INTRODUCTION TO MAP MATCHING FOR PERSONAL NAVIGATION ASSISTANTS," 1998.

[224] C. E. White, D. Bernstein, and A. L. Kornhauser, "Some map matching algorithms for personal navigation assistants," Transportation Research Part C: Emerging Technologies, vol. 8, pp. 91-108, 2// 2000.

[225] Y. Zhao, Vehicle Location and Navigation System. London, UK: Artech House Print on Demand, 1997.

[226] K. S. Washington Y. Ochieng, David Walsh, Gary Brodin, Steve Griffin and Mark Denney, "GPS Integrity and Potential Impact on Aviation Safety," THE JOURNAL OF NAVIGATION, vol. 56, pp. $51-65,2003$.

[227] J. S. Greenfeld, "Matching GPS observations to locations on a digital map," in Proceedings of the 81st Annual Meeting of the Transportation Research Board, 2002.

[228] M. A. Quddus, W. Y. Ochieng, L. Zhao, and R. B. Noland, "A general map matching algorithm for transport telematics applications," GPS Solutions, vol. 7, pp. 157-167, 2003// 2003.

[229] M. E. El Najjar and P. Bonnifait, "A Road-Matching Method for Precise Vehicle Localization Using Belief Theory and Kalman Filtering," Autonomous Robots, vol. 19, pp. 173-191, 2005// 2005.

[230] M. A. Quddus, R. B. Noland, and W. Y. Ochieng, "A High Accuracy Fuzzy Logic Based Map Matching Algorithm for Road Transport," Journal of Intelligent Transportation Systems, vol. 10, pp. 103-115, 2006/09/01 2006.

[231] P. Jong-Sun, S. Dong-Ho, and S. Tae-Kyung, "Development of a map matching method using the multiple hypothesis technique," in ITSC 2001. 2001 IEEE Intelligent Transportation Systems. Proceedings (Cat. No.01TH8585), 2001, pp. 23-27.

[232] Y. Dakai, C. Baigen, and Y. Yifang, "An improved map-matching algorithm used in vehicle navigation system," in Proceedings of the 2003 IEEE International Conference on Intelligent Transportation Systems, 2003, pp. 1246-1250 vol.2.

[233] Z. Li and W. Chen, "A new approach to map-matching and parameter correcting for vehicle navigation system in the area of shadow of GPS signal," in Proceedings. 2005 IEEE Intelligent Transportation Systems, 2005., 2005, pp. 449-454. 
[234] M. Hashemi and H. A. Karimi, "A critical review of real-time map-matching algorithms: Current issues and future directions," Computers, Environment and Urban Systems, vol. 48, pp. 153-165, 11// 2014.

[235] M. A. Quddus, W. Y. Ochieng, and R. B. Noland, "Current map-matching algorithms for transport applications: State-of-the art and future research directions," Transportation Research Part C: Emerging Technologies, vol. 15, pp. 312-328, 10// 2007.

[236] D. Nister and H. Stewenius, "Scalable Recognition with a Vocabulary Tree," in 2006 IEEE Computer Society Conference on Computer Vision and Pattern Recognition (CVPR'06), 2006, pp. 2161-2168.

[237] R. Clark, N. Trigoni, and A. Markham, "Robust vision-based indoor localization," presented at the Proceedings of the 14th International Conference on Information Processing in Sensor Networks, Seattle, Washington, 2015.

[238] D. Y. Li Deng, Deep Learning: Methods and Applications. Foundations and Trends in Signal Processing vol. 7: Microsoft Inc., 2013.

[239] A. K. T. R. Kumar, B. Schäufele, D. Becker, O. Sawade, and I. Radusch, "Indoor localization of vehicles using Deep Learning," in 2016 IEEE 17th International Symposium on A World of Wireless, Mobile and Multimedia Networks (WoWMoM), 2016, pp. 1-6.

[240] X. Wang, L. Gao, S. Mao, and S. Pandey, "DeepFi: Deep learning for indoor fingerprinting using channel state information," in 2015 IEEE Wireless Communications and Networking Conference (WCNC), 2015, pp. 1666-1671.

[241] X. Wang, L. Gao, and S. Mao, "BiLoc: Bi-Modal Deep Learning for Indoor Localization With Commodity 5GHz WiFi," IEEE Access, vol. 5, pp. 4209-4220, 2017.

[242] X. Wang, L. Gao, and S. Mao, "PhaseFi: Phase Fingerprinting for Indoor Localization with a Deep Learning Approach," in 2015 IEEE Global Communications Conference (GLOBECOM), 2015, pp. 1-6.

[243] L. K. Alazzawi, A. M. Elkateeb, A. Ramesh, and W. Aljuhar, "Scalability Analysis for Wireless Sensor Networks Routing Protocols," pp. 139-144, 2008.

[244] J. W. M. Cardei, "Coverage in Wireless Sensor Networks," Handbook of Sensor Networks, vol. 21, pp. $1-18,2007$.

[245] I. Stojmenovic, Handbook of Sensor Networks - Algorithm and Architecture. United States of America: John Wiley \& Sons, Inc., Hoboken, New Jersey, 2005.

[246] L. Zheng, W. Zhou, W. Tang, X. Zheng, A. Peng, and H. Zheng, "A 3D indoor positioning system based on low-cost MEMS sensors," Simulation Modelling Practice and Theory, vol. 65, pp. 45-56, 6// 2016.

[247] J. Haverinen and A. Kemppainen, "Global indoor self-localization based on the ambient magnetic field," Robotics and Autonomous Systems, vol. 57, pp. 1028-1035, 10/31/ 2009.

[248] J. Jung, T. Oh, and H. Myung, "Magnetic field constraints and sequence-based matching for indoor pose graph SLAM," Robotics and Autonomous Systems, vol. 70, pp. 92-105, 8// 2015.

[249] H. Chao, F. Zhongqing, R. Yupeng, C. Yueyue, L. Haixiang, W. Kai, et al., "An efficient magnetic localization system for indoor planar mobile robot," in Control Conference (CCC), 2015 34th Chinese, 2015, pp. 4899-4904.

[250] X. Tan and Z. Sun, "Environment-Aware Indoor Localization Using Magnetic Induction," in 2015 IEEE Global Communications Conference (GLOBECOM), 2015, pp. 1-6.

[251] M. Frassl, M. Angermann, M. Lichtenstern, P. Robertson, B. J. Julian, and M. Doniec, "Magnetic maps of indoor environments for precise localization of legged and non-legged locomotion," in 2013 IEEE/RSJ International Conference on Intelligent Robots and Systems, 2013, pp. 913-920.

[252] N. Akai and K. Ozaki, "Gaussian processes for magnetic map-based localization in large-scale indoor environments," in Intelligent Robots and Systems (IROS), 2015 IEEE/RSJ International Conference on, 2015, pp. 4459-4464.

[253] S. i. Ko, J. s. Choi, and B. h. Kim, "Performance Enhancement of Indoor Mobile Localization System using Unscented Kalman Filter," in SICE-ICASE, 2006. International Joint Conference, 2006, pp. $1355-1360$.

[254] J. Kemper and H. Linde, "Challenges of passive infrared indoor localization," in Positioning, Navigation and Communication, 2008. WPNC 2008. 5th Workshop on, 2008, pp. 63-70.

[255] M. Hazas and A. Hopper, "Broadband ultrasonic location systems for improved indoor positioning," IEEE Transactions on Mobile Computing, vol. 5, pp. 536-547, 2006.

[256] S. Bertrand, J. Marzat, M. Carton, C. Chaix, P. Varela, R. Waroux, et al., "A low-cost system for indoor motion tracking of unmanned aerial vehicles," in Intelligent Sensors, Sensor Networks and Information Processing (ISSNIP), 2011 Seventh International Conference on, 2011, pp. 574-579.

[257] J. M. Kahn and J. R. Barry, "Wireless infrared communications," Proceedings of the IEEE, vol. 85, pp. 265-298, 1997. 
[258] N. Yoshiyuki, K. Ryosuke, M. Masateru, and N. Takuichi, "Implementation of indoor location and orientation estimation system using ultrasonic and radio," in SICE, 2007 Annual Conference, 2007, pp. 2468-2472.

[259] F. Subhan, H. Hasbullah, A. Rozyyev, and S. T. Bakhsh, "Indoor positioning in Bluetooth networks using fingerprinting and lateration approach," in Information Science and Applications (ICISA), 2011 International Conference on, 2011, pp. 1-9.

[260] P. Loreti, P. Sperandio, and M. Baldasseroni, "A multi-technology indoor positioning service to enable new location-aware applications," in Satellite Telecommunications (ESTEL), 2012 IEEE First AESS European Conference on, 2012, pp. 1-6.

[261] X. Xie, H. Lu, and T. B. Pedersen, "Efficient distance-aware query evaluation on indoor moving objects," in Data Engineering (ICDE), 2013 IEEE 29th International Conference on, 2013, pp. 434445.

[262] M. Gunawan, B. Li, T. Gallagher, A. G. Dempster, and G. Retscher, "A new method to generate and maintain a WiFi fingerprinting database automatically by using RFID," in Indoor Positioning and Indoor Navigation (IPIN), 2012 International Conference on, 2012, pp. 1-6.

[263] Z. Yao, D. Liang, W. Jiang, H. Bo, and F. Yuzhuo, "Implementing indoor positioning system via ZigBee devices," in Signals, Systems and Computers, 2008 42nd Asilomar Conference on, 2008, pp. 1867-1871.

[264] H. Bin, C. Zhong, and F. Suzhong, "The study of new generation of indoor positioning technology applied in exhibitions," in Advanced Intelligence and Awareness Internet (AIAI 2011), 2011 International Conference on, 2011, pp. 399-402.

[265] N. Y. Keong, K. S. Chieh, M. F. Burhan, N. Balasubramaniam, and N. M. Din, "RFID and ZigBee integrated environment for indoor localization," in Engineering Technology and Technopreneuship (ICE2T), 2014 4th International Conference on, 2014, pp. 213-217.

[266] W. Longkang, N. Baisheng, Z. Ruming, Z. Shengrui, and L. Hailong, "Zigbee-Based Positioning System For Coal Miners," Procedia Engineering, vol. 26, pp. 2406-2414, // 2011.

[267] E. Garcia, P. Poudereux, A. Hernandez, J. Urena, and D. Gualda, "A robust UWB indoor positioning system for highly complex environments," in Industrial Technology (ICIT), 2015 IEEE International Conference on, 2015, pp. 3386-3391.

[268] M. Kuhn, C. Zhang, M. Mahfouz, and A. Fathy, "Real-time UWB indoor positioning system with millimeter 3-D dynamic accuracy," in Antennas and Propagation Society International Symposium, 2009. APSURSI '09. IEEE, 2009, pp. 1-4.

[269] L. Mainetti, L. Patrono, and I. Sergi, "A survey on indoor positioning systems," in Software, Telecommunications and Computer Networks (SoftCOM), 2014 22nd International Conference on, 2014, pp. 111-120.

[270] N. Pathanawongthum and P. Cherntanomwong, "RFID based localization techniques for indoor environment," in Advanced Communication Technology (ICACT), 2010 The 12th International Conference on, 2010, pp. 1418-1421.

[271] H. Ji, L. Xie, C. Wang, Y. Yin, and S. Lu, "CrowdSensing: A crowd-sourcing based indoor navigation using RFID-based delay tolerant network," Journal of Network and Computer Applications, vol. 52, pp. 79-89, 6// 2015.

[272] Z. Yang, P. Zhang, and L. Chen, "RFID-enabled indoor positioning method for a real-time manufacturing execution system using OS-ELM," Neurocomputing, vol. 174, Part A, pp. 121-133, 1/22/ 2016.

[273] S. Park and S. Hashimoto, "An intelligent localization algorithm using read time of RFID system," Advanced Engineering Informatics, vol. 24, pp. 490-497, 11// 2010.

[274] T. C. C. Brignone, G. Lyon, S. Pradhan, "SmartLOCUS: An autonomous, self-assembling sensor network for indoor asset and systems management," Hewlett-Packard Development Company, L.P., USA2005.

[275] C. Medina, I. Alvarez, J. C. Segura, A. de la Torre, and C. Benitez, "TELIAMADE ultrasonic indoor location system: Application as a teaching tool," in Acoustics, Speech and Signal Processing (ICASSP), 2012 IEEE International Conference on, 2012, pp. 2777-2780.

[276] N. B. Priyantha, "The Cricket Indoor Location System," PhD, Department of Electrical Engineering and Computer Science, MASSACHUSETTS INSTITUTE OF TECHNOLOGY, USA, 2005.

[277] R. Want and A. Hopper, "Active badges and personal interactive computing objects," Consumer Electronics, IEEE Transactions on, vol. 38, pp. 10-20, 1992.

[278] Firefly Motion Tracking System User Guide. Available: http://www.gesturecentral.com/FireflyUserGuide.pdf

[279] Optotrak. Available: http://www.ndigital.com 
[280] V. N. Vapnik, "The Nature of statistical Learning Theory.," AT\&T Bell Labs, USA1995.

[281] E. Aitenbichler and M. Muhlhauser, "An IR local positioning system for smart items and devices," in Distributed Computing Systems Workshops, 2003. Proceedings. 23rd International Conference on, 2003, pp. 334-339.

[282] TOPAZ Local Positioning System. Available: http://www.tadlys.co.il

[283] ZONITH Indoor Positioning System. Available: http://www.zonith.com/products/ips

[284] A. Cavallini, "iBeacon Bible 1.0."

[285] P. Bahl and V. N. Padmanabhan, "RADAR: an in-building RF-based user location and tracking system," in INFOCOM 2000. Nineteenth Annual Joint Conference of the IEEE Computer and Communications Societies. Proceedings. IEEE, 2000, pp. 775-784 vol.2.

[286] Ekahau: Real-Time Location System. Available: http://www.ekahau.com/real-time-locationsystem/technology/

[287] M. A. Youssef, A. Agrawala, and A. Udaya Shankar, "WLAN location determination via clustering and probability distributions," in Pervasive Computing and Communications, 2003. (PerCom 2003). Proceedings of the First IEEE International Conference on, 2003, pp. 143-150.

[288] M. Youssef and A. Agrawala, "Handling samples correlation in the Horus system," in INFOCOM 2004. Twenty-third AnnualJoint Conference of the IEEE Computer and Communications Societies, 2004, pp. 1023-1031 vol.2.

[289] R. Hansen, B. Thomsen, L. L. Thomsen, and F. S. Adamsen, "SmartCampusAAU -- An Open Platform Enabling Indoor Positioning and Navigation," in Mobile Data Management (MDM), 2013 IEEE 14th International Conference on, 2013, pp. 33-38.

[290] P. Castro, P. Chiu, T. Kremenek, and R. Muntz, "Ubicomp 2001: Ubiquitous Computing," in Lecture Notes in Computer Science. vol. 2201, G. D. Abowd, B. Brumitt, and S. Shafer, Eds., ed Atlanta, Georgia: Springer-Verlag, 2001, pp. 18-34.

[291] M. Wallbaum, "WhereMoPS: an indoor geolocation system," in Personal, Indoor and Mobile Radio Communications, 2002. The 13th IEEE International Symposium on, 2002, pp. 1967-1971 vol.4.

[292] "CC2431," Texas Instrument, USA.

[293] C. C.-T. H. Chih-Ning, "ZigBEACON: ZigBee-based indoor location system by K-nearest neighbor algorithm with weighted RSSI," Institute of Biomedical Engineering, National Yang-Ming University,December 20112011.

[294] C. Phan, "Performance Evaluation of a UWB-RFID System for Potential Space Applications," NASA, USA.

[295] Zebra Dart UWB. Available: http://www.zebra.com

[296] Ubisense. Available: http://www.ubisense.net

[297] DecaWave Scensor. Available: www.decawave.com/products/dw1000

[298] L. M. Ni, L. Yunhao, L. Yiu Cho, and A. P. Patil, "LANDMARC: indoor location sensing using active RFID," in Pervasive Computing and Communications, 2003. (PerCom 2003). Proceedings of the First IEEE International Conference on, 2003, pp. 407-415.

[299] G. B. J. Hightower, R. Want, "SpotON: An Indoor 3D Location Sensing Technology Based on RF Signal Strength," University of Washington, Washington, USAFebruary 182000.

[300] Zebra Technology Company. Available: http://www.Wherenet.com/

[301] V. N. P. P. Bahl, A. Balachandran "Enhancements to the RADAR User Location and Tracking System," Microsoft Corporation, WA, USA MSR-TR-2000-12, February 20002000.

[302] F. Evennou and F. Marx, "Advanced Integration of WiFi and Inertial Navigation Systems for Indoor Mobile Positioning," EURASIP Journal on Advances in Signal Processing, vol. 2006, p. 086706, 2006.

[303] G. Retscher, "Location Determination in Indoor Environments for Pedestrian Navigation," in 2006 IEEE/ION Position, Location, And Navigation Symposium, 2006, pp. 547-555.

[304] Y. Li, Y. Zhuang, P. Zhang, H. Lan, X. Niu, and N. El-Sheimy, "An improved inertial/wifi/magnetic fusion structure for indoor navigation," Information Fusion, vol. 34, pp. 101-119, 3// 2017.

[305] Q. Fu and G. Retscher, "Using RFID and INS for Indoor Positioning," in Location Based Services and TeleCartography II: From Sensor Fusion to Context Models, G. Gartner and K. Rehrl, Eds., ed Berlin, Heidelberg: Springer Berlin Heidelberg, 2009, pp. 421-438.

[306] P. Coronel, S. Furrer, W. Schott, and B. Weiss, "Indoor location tracking using inertial navigation sensors and radio beacons," presented at the Proceedings of the 1st international conference on The internet of things, Zurich, Switzerland, 2008.

[307] A. Ramos, A. Lazaro, R. Villarino, and D. Girbau, "Time-domain UWB RFID tags for smart floor applications," in RFID Technology and Applications Conference (RFID-TA), 2014 IEEE, 2014, pp. 165-169. 
[308] S. Holm, "Hybrid ultrasound-RFID indoor positioning: Combining the best of both worlds," in 2009 IEEE International Conference on RFID, 2009, pp. 155-162.

[309] E. S. Lohan, K. Koski, J. Talvitie, and L. Ukkonen, "WLAN and RFID Propagation channels for hybrid indoor positioning," in Localization and GNSS (ICL-GNSS), 2014 International Conference on, 2014, pp. 1-6.

[310] F. Feng, H. Shengyu, and X. Qi, "The Research of the ZigBee and RFID Fusion Technology in the Coal Mine Safety," in Information Management, Innovation Management and Industrial Engineering (ICIII), 2010 International Conference on, 2010, pp. 32-36.

[311] F. Zampella, A. R. J. R, and F. Seco, "Robust indoor positioning fusing PDR and RF technologies: The RFID and UWB case," in Indoor Positioning and Indoor Navigation (IPIN), 2013 International Conference on, 2013, pp. 1-10.

[312] A. Papapostolou and H. Chaouchi, "Exploiting multi-modality and diversity for localization enhancement: WiFi \&\#x00026; RFID usecase," in Personal, Indoor and Mobile Radio Communications, 2009 IEEE 20th International Symposium on, 2009, pp. 1903-1907.

[313] A. Patarot, M. Boukallel, S. Lamy-Perbal, A. Vervisch-Picois, and N. Samama, "INS and GNSS fusion enhancement based on a weighted reliabilities approach," in Indoor Positioning and Indoor Navigation (IPIN), 2012 International Conference on, 2012, pp. 1-10.

[314] S. Zirari, P. Canalda, and F. Spies, "WiFi GPS based combined positioning algorithm," in Wireless Communications, Networking and Information Security (WCNIS), 2010 IEEE International Conference on, 2010, pp. 684-688.

[315] A. Bahillo, S. Mazuelas, J. Prieto, P. Fern, x00E, ndez, et al., "Hybrid RSS-RTT localization scheme for wireless networks," in Indoor Positioning and Indoor Navigation (IPIN), 2010 International Conference on, 2010, pp. 1-7.

[316] B. Q. Ferreira, J. Gomes, and J. P. Costeira, "A unified approach for hybrid source localization based on ranges and video," in 2015 IEEE International Conference on Acoustics, Speech and Signal Processing (ICASSP), 2015, pp. 2879-2883.

[317] Z. Juan and J. Hongdong, "A hybrid localization algorithm based on DV-Distance and the twiceweighted centroid for WSN," in Computer Science and Information Technology (ICCSIT), 2010 3rd IEEE International Conference on, 2010, pp. 590-594.

[318] W. Liu, C. Hu, Q. He, M. Q. H. Meng, and L. Liu, "An hybrid localization system based on optics and magnetics," in Robotics and Biomimetics (ROBIO), 2010 IEEE International Conference on, 2010, pp. $1165-1169$.

[319] N. A. M. Maung and M. Kawai, "Hybrid RSS-SOM localization scheme for wireless ad hoc and sensor networks," in Indoor Positioning and Indoor Navigation (IPIN), 2012 International Conference on, 2012, pp. 1-7.

[320] Y. Shu, C. Bo, G. Shen, C. Zhao, L. Li, and F. Zhao, "Magicol: Indoor Localization Using Pervasive Magnetic Field and Opportunistic WiFi Sensing," IEEE Journal on Selected Areas in Communications, vol. 33, pp. 1443-1457, 2015.

[321] I. Bisio, A. Sciarrone, and S. Zappatore, "A new asset tracking architecture integrating RFID, Bluetooth Low Energy tags and ad hoc smartphone applications," Pervasive and Mobile Computing.

[322] X. Song, X. Li, W. Tang, and W. Zhang, "A fusion strategy for reliable vehicle positioning utilizing RFID and in-vehicle sensors," Information Fusion, vol. 31, pp. 76-86, 9// 2016. 